\title{
Discharge communication practices in pediatric emergency care: a systematic review and narrative synthesis
}

Janet A. Curran 1* D, Allyson J. Gallant', Roger Zemek², Amanda S. Newton ${ }^{3}$, Mona Jabbour $^{2}$, Jill Chorney ${ }^{4}$, Andrea Murphy ${ }^{5}$, Lisa Hartling ${ }^{3}$, Kate MacWilliams', Amy Plint ${ }^{2}$, Shannon MacPhee ${ }^{4}$, Andrea Bishop ${ }^{1}$ and Samuel G. Campbell ${ }^{6}$

\begin{abstract}
Background: The majority of children receiving care in the emergency department (ED) are discharged home, making discharge communication a key component of quality emergency care. Parents must have the knowledge and skills to effectively manage their child's ongoing care at home. Parental fatigue and stress, health literacy, and the fragmented nature of communication in the ED setting may contribute to suboptimal parent comprehension of discharge instructions and inappropriate ED return visits. The aim of this study was to examine how and why discharge communication works in a pediatric ED context and develop recommendations for practice, policy, and research.
\end{abstract}

Methods: We systematically reviewed the published and gray literature. We searched electronic databases CINAHL, Medline, and Embase up to July 2017. Policies guiding discharge communication were also sought from pediatric emergency networks in Canada, USA, Australia, and the UK. Eligible studies included children less than 19 years of age with a focus on discharge communication in the ED as the primary objective. Included studies were appraised using relevant Joanna Briggs Institute (JBI) checklists. Textual summaries, content analysis, and conceptual mapping assisted with exploring relationships within and between data. We implemented an integrated knowledge translation approach to strengthen the relevancy of our research questions and assist with summarizing our findings.

Results: A total of 5095 studies were identified in the initial search, with 75 articles included in the final review. Included studies focused on a range of illness presentations and employed a variety of strategies to deliver discharge instructions. Education was the most common intervention and the majority of studies targeted parent knowledge or behavior. Few interventions attempted to change healthcare provider knowledge or behavior. Assessing barriers to implementation, identifying relevant ED contextual factors, and understanding provider and patient attitudes and beliefs about discharge communication were identified as important factors for improving discharge communication practice.

Conclusion: Existing literature examining discharge communication in pediatric emergency care varies widely. A theory-based approach to intervention design is needed to improve our understanding regarding discharge communication practice. Strengthening discharge communication in a pediatric emergency context presents a significant opportunity for improving parent comprehension and health outcomes for children.

Systematic review registration: PROSPERO registration number: CRD42014007106.

Keywords: Discharge communication, Pediatric emergency care, Caregivers, Systematic review, Narrative synthesis, Integrated knowledge translation

\footnotetext{
*Correspondence: jacurran@dal.ca

'School of Nursing, Dalhousie University, 5869 University Ave., PO Box 15000,

Halifax, NS B3H 4R2, Canada

Full list of author information is available at the end of the article
}

(c) The Author(s). 2019 Open Access This article is distributed under the terms of the Creative Commons Attribution 4.0 International License (http://creativecommons.org/licenses/by/4.0/), which permits unrestricted use, distribution, and reproduction in any medium, provided you give appropriate credit to the original author(s) and the source, provide a link to the Creative Commons license, and indicate if changes were made. The Creative Commons Public Domain Dedication waiver (http://creativecommons.org/publicdomain/zero/1.0/) applies to the data made available in this article, unless otherwise stated. 


\section{Background}

The discharge process in a pediatric emergency department (ED) can introduce vulnerability for parents and caregivers. Attention to this phenomenon is critical given that following a visit to the ED the majority of children are discharged home under the care of their parents $[1,2]$. Ideally, parents should depart the ED with the necessary knowledge and skills to effectively manage their children's care at home. However, following ED discharge, many caregivers and patients are unable to specify their diagnosis, list medications they received, outline post-ED care, or identify when to seek further medical attention [3-5]. The discharge process should include communication of important information about the child's illness, verification of comprehension, and tailoring of the discharge instructions to address areas of misunderstanding [6]. Yet, this is not always the parents' experience, and evidence supports that poor quality ED discharge communication can impact subsequent health care utilization, including unscheduled return visits to the ED [7, 8]. Comprehension of discharge communication has been shown to be an important factor in promoting adherence to discharge instructions and preventing unnecessary return visits; however, comprehension is rarely assessed in practice [9]. A number of factors are known to impact comprehension including quality of the communication provided [10], health literacy, numeracy, and reading ability [11-13].

A number of recent reviews have explored discharge communication, including a recent systematic review to establish the cost-effectiveness of implementing electronic discharge communication to support the transition between acute and community care [14]. Another review focused on the parent management of inpatient and ED discharge instructions [15]. We conducted a systematic review and narrative synthesis of the discharge communication literature to gain a better understanding of how and why discharge communication functions in a pediatric ED context and to inform the development of recommendations for future research, policy, and practice change. Our review addressed the following questions: (1) What types of interventions, processes, and policies have been examined regarding discharge communication in a pediatric ED context and (2) How does the discharge process impact parent, patient, and provider outcomes?

\section{Methods}

\section{Study design}

We conducted a systematic review with narrative synthesis following methods outlined by Popay et al. [16]. This type of review explores relationships within and between studies [17]. Techniques are employed to expose the context and characteristics of the included studies to facilitate comparison of similarities and differences across studies [18]. Further details of the review protocol have been published elsewhere [19]. The protocol was registered with PROSPERO (CRD42014007106).

We embedded an integrated knowledge translation (iKT) approach in our review, whereby we met with key knowledge users (e.g., ED clinicians, administrators, parents, and researchers) during each stage of the review to strengthen the relevancy of our research questions and tailor our recommendations. We employed a number of communication strategies to maximize engagement including email and face-to-face and teleconference meetings. Critical reflection of engagement was conducted through detailed documentation of team discussions at all meetings, outlining input from the different stakeholder groups, and underlying rationale for decisions made at each stage of the synthesis process. We also integrated a knowledge user check-in strategy, where at regular intervals during each meeting, we paused to summarize the discussion and solicit questions. Three key meetings included (1) a teleconference to refine the research question, (2) a face-to-face meeting to discuss the results of the preliminary analysis, and (3) a teleconference meeting to discuss findings and draft recommendations. Finally, authors from three of the included studies (all ED physicians from academic teaching hospitals) were contacted by email and invited to provide feedback on the preliminary findings. Expert feedback was provided through a brief telephone interview lasting 15-30 min.

We used the Behaviour Change Wheel (BCW) [20], a theory-based method for characterizing and designing behavior change interventions, as a guiding framework to examine the discharge communication interventions in the included studies. Pairs of two reviewers (KM, MB, AG, or JAC) independently coded the narrative descriptions of all interventions. A directed content analysis approach was used to classify intervention description according to the nine intervention function types (i.e., the mechanism by which the intervention is proposed to function) of the $\mathrm{BCW}$ [20]. Reviewers met to compare consistency after coding the first and third study and then after every five studies. Differences in coding were discussed to achieve consensus.

We also coded the 75 included studies to identify barriers and enablers to intervention implementation and effectiveness as reported by the study author. Full text articles were loaded into NVivo (QSR International) and were coded by two reviewers (JAC and AG) [21]. Reviewers met throughout the process to ensure consistent coding of barriers and enablers and to discuss sections that were challenging to code.

\section{Search strategy}

The search strategy was developed in consultation with a library scientist and peer reviewed by a second library 
scientist from the Alberta Research Centre for Child Health Evidence (ARCHE; University of Alberta) prior to being implemented in three databases from their date of inception to July 7th, 2017: CINAHL, Medline, and Embase. Please see Additional file 1 for the list of all search strategy terms. We also hand-searched relevant emergency pediatric journals for articles published between January 1st, 2009 and October 31st, 2018: Annals of Emergency Medicine, Academic Emergency Medicine, Pediatric Emergency Care, Journal of Emergency Medicine, and Journal of Emergency Nursing. Additionally, a further search was conducted by emailing the ED administrators of the 15 Pediatric Emergency Research Canada (PERC) sites and the Chairs of the Pediatric Research in Emergency Departments International Collaborative (PREDICT), Pediatric Emergency Medicine Collaborative Research Committee (PEM-CRC), Pediatric Emergency Care Applied Research Network (PECARN), and the Paediatric Emergency Research in the United Kingdom \& Ireland (PERUKI) and reviewing relevant national and international websites to identify existing discharge communication policies and procedures that might be relevant in a pediatric ED context.

\section{Study selection}

Studies were included if they described or evaluated changes in the structure or process of care in the ED to enhance discharge communication as their primary objective. Quantitative, qualitative, and mixed methods study designs were eligible for inclusion. Studies were excluded if interventions took place outside of the ED or primary outcomes were not relevant to discharge communication. The published protocol paper for this review provides further details on the process of selecting studies [19]. Detailed inclusion and exclusion criteria for studies and abstracts can be found in Additional file 2 .

\section{Data extraction}

Data were extracted by teams of two independent reviewers using a customized data abstraction form and discrepancies were assessed by JAC. Full data extraction included study design details (i.e., year of publication, country, type of ED), detailed description of the intervention (i.e., description of individual components, reported use of theory or assumptions about causal mechanisms supporting the different components, duration, and timing of the intervention), implementation strategies (i.e., training or instructions provided to participants, timing), participant details (i.e., age of the child, illness presentation, parent characteristics, health care provider characteristics), and author reported factors and/or processes identified as impacting implementation. Our primary outcome of interest was any change in process, parent, healthcare provider, or patient outcome related to the discharge communication intervention. We extracted details about authored reported primary outcomes (i.e., timing, measures, target of the intervention). Data was managed using excel and intervention descriptions were exported to NVivo 10 (QSR International) for analysis [19].

\section{Quality assessment}

Study quality was assessed at the study level by two independent reviewers using critical appraisal checklists from Joanna Briggs Institute (JBI) [22]. Each study was appraised using the appropriate checklist for the study design. JBI checklists are designed to assess the quality of a study's methodologies and outcomes, and to identify potential sources of bias or confounding variables within the study [22]. Options for checklist responses included "yes," "no," "unclear," or "not applicable." Each reviewer used the JBI definitions and checklists and provided evidence from the article to support the reasoning for their scoring. At two points in the appraisal process, the reviewers met to meet consensus and resolve discrepancies. A third reviewer was consulted when discrepancies could not be resolved.

\section{Data synthesis}

The primary aim of this review was to understand how and why discharge communication interventions and processes work in a pediatric ED context. To address this aim, we employed a number of data synthesis strategies proposed by Popay et al. [16] to examine the individual study findings. We developed summary tables, which outlined study design, clinical context, intervention components, intervention target, quality appraisal, outcome measures, and direction of effect. Findings of included studies did not lend themselves to quantitative analysis due to the wide range of intervention descriptions and outcome measures. We also developed structured textual summaries of all included studies that outlined primary objectives, details regarding context and setting, descriptions of any interventions and implementation strategies, relevant outcomes, and barriers reported by study authors. Content analysis was carried out on all extracted data to assist with identifying importing themes and gaps in the existing evidence.

\section{Results}

A total of 5095 studies were identified by the search. Of these studies, 4734 studies were excluded at the title and abstract phase and 342 were eligible for full text screening. A total of 265 articles were excluded at the full text screening stage (see Additional File 3), resulting in 75 articles included in the review (Fig. 1). Half of the included papers were observational studies $(n=37)[23-59]$ and $47 \%(n=35)$ were either randomized controlled trials 


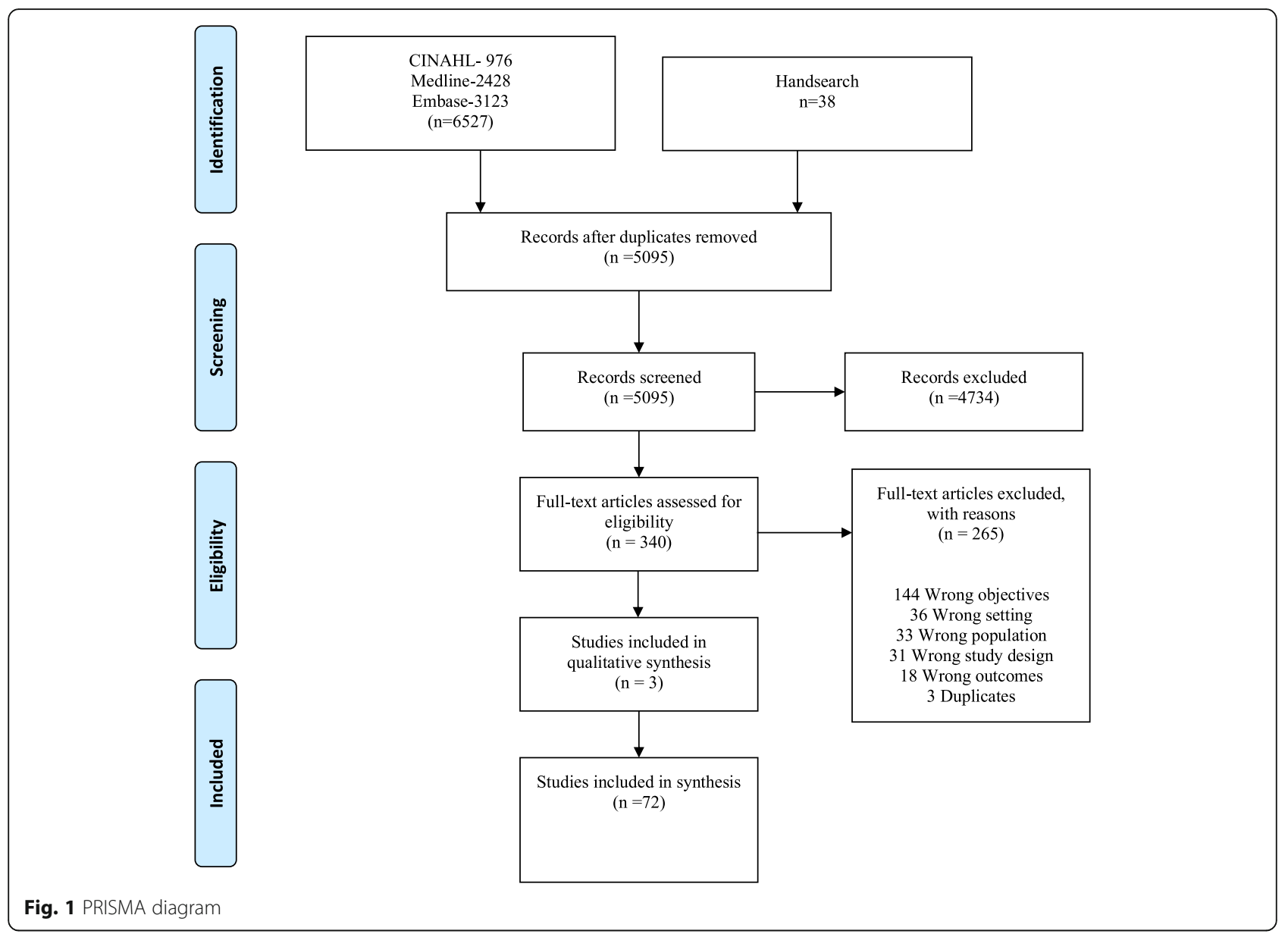

(RCT) or quasi-experimental studies [60-94]. Three qualitative studies were also included [95-97]. Characteristics of the included studies are presented in Table 1. Detailed about excluded studies can be found in additional Table 2. Included studies covered a range of settings: pediatric ED, mixed ED (adult and pediatric), urban, rural, and academic teaching facilities. Although included studies focused on a variety of illness presentations, asthma $(n=20)$ was the most common $[27,29,39$, $42,46,61,62,65,67,70,75,77,79-83,85,89,90]$. Other common illnesses were minor head injury $(n=12)$ $[30,34,36,44,48,50,51,56,58,68,86,94]$ and fever $(n=9)[35,46,64,67,68,71,72,78,88]$. Outcomes varied across included studies but primarily involved improving parent adherence with discharge instructions or follow-up appointments $(n=12)[60,61,66,75,77,81-$ $85,90,93]$, improving parent knowledge of illness treatment $(n=7)[63,65,67,68,70-72]$, and reducing unnecessary return ED visits $(n=5)[62,64,69,88,89]$. All studies were published from 1979 to 2018, with just over half $(n=41)$ of the studies published since 2009 [23-25, $30,32-34,37,40,42,44-52,55,56,59,61,64-68,71-$ $73,75,76,79,81,83,85,92,94,96,97]$.

\section{Quality of the evidence}

Study quality was assessed using critical appraisal checklists from the Joanna Briggs Institute (JBI) [22]. The majority of the cross-sectional studies were of moderate quality (6/8 appraisal criteria present). The two appraisal questions that had mixed results were related to identifying and addressing potential confounding. Only a third of the studies $(n=9 ; 32 \%)$ identified possible confounders and even fewer studies noted how these confounders were adjusted for during data analysis $(n=8 ; 29 \%)$.

The 24 RCT were appraised using the Checklist for Randomized Controlled Trials and $46 \%$ of the studies $(n=11)$ did not clearly identify if a true randomization method was used. Additionally, only four RCT clearly stated how allocation concealment was used during the study [60-63].

The Checklist for Quasi-Experimental Studies was used for 11 studies in the review. These quasiexperimental studies $(n=11)$ scored consistently well across all of the appraisal checklist criteria, with the exception of concerns about composition of the comparison groups. We found that just over half of studies $(n=6 ; 55 \%)$ had at least one or more key variables with 


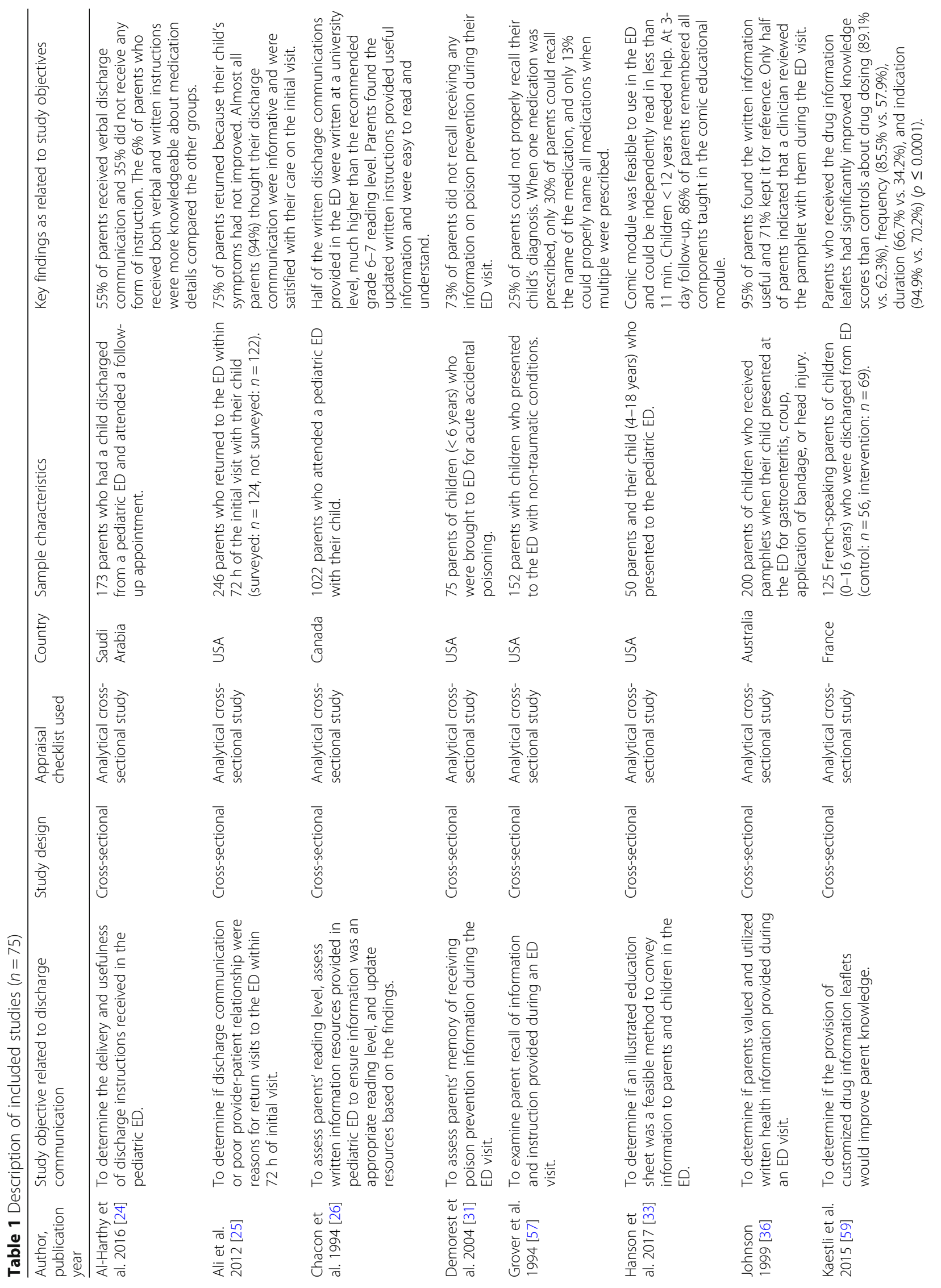




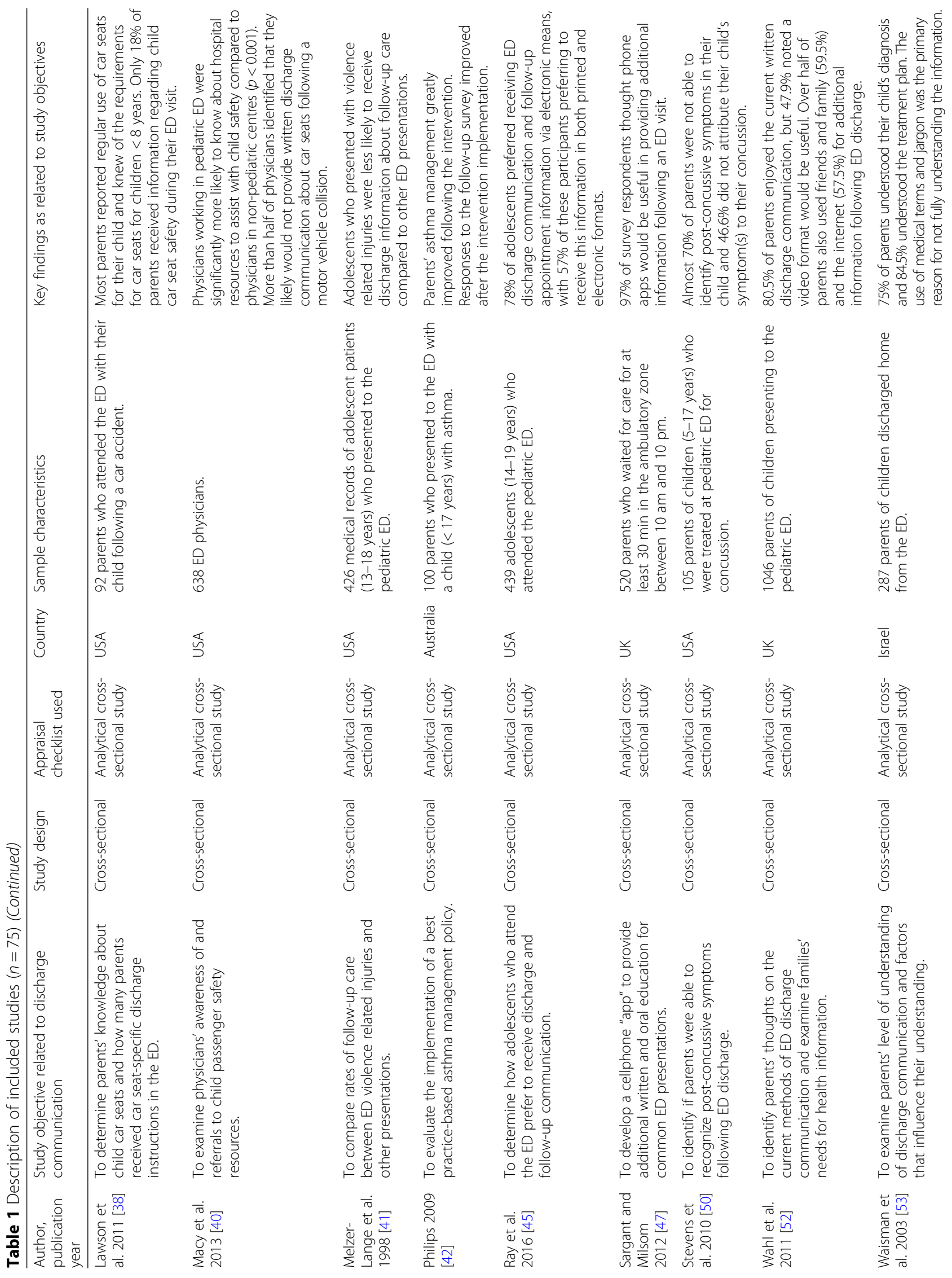




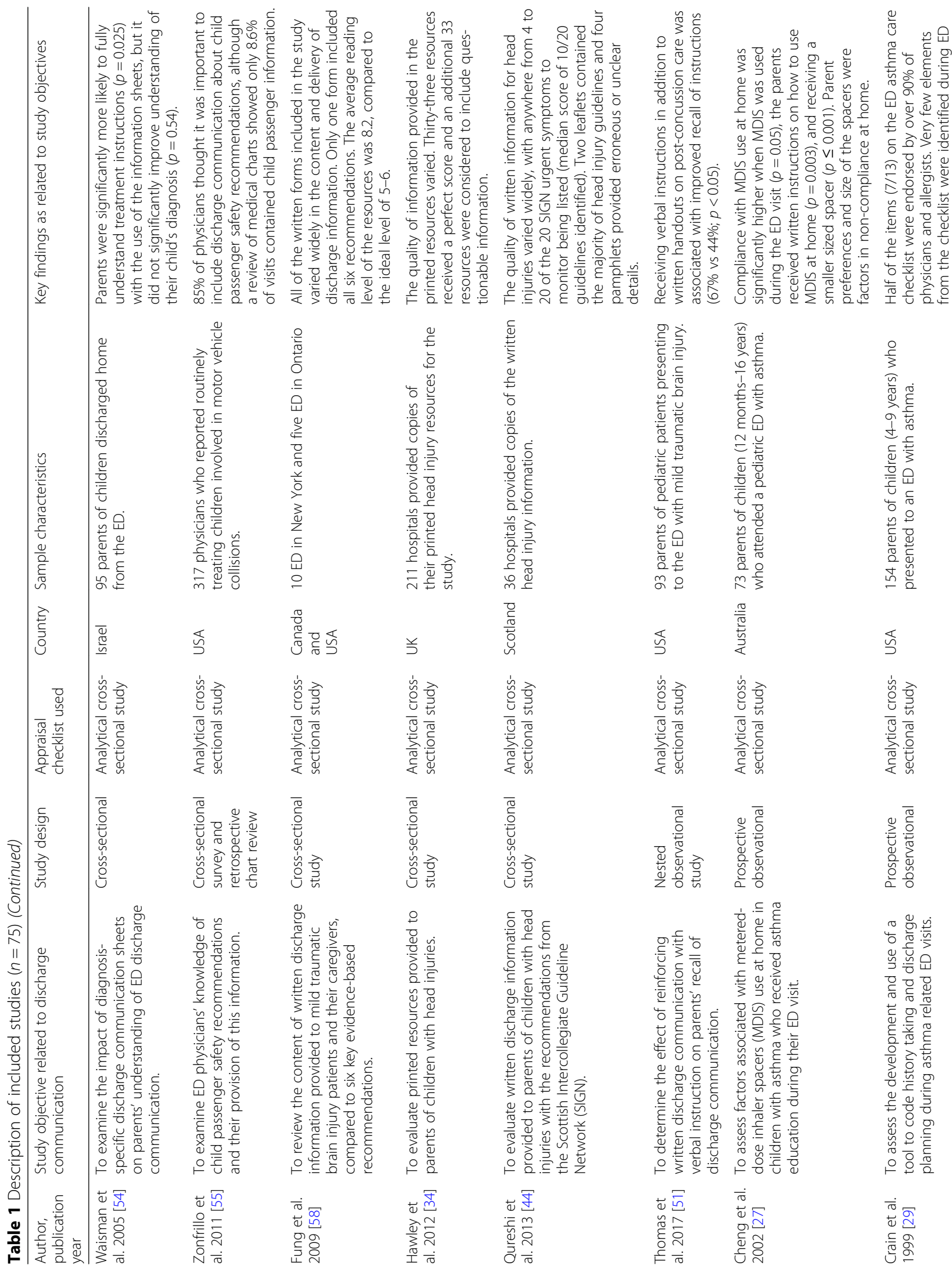




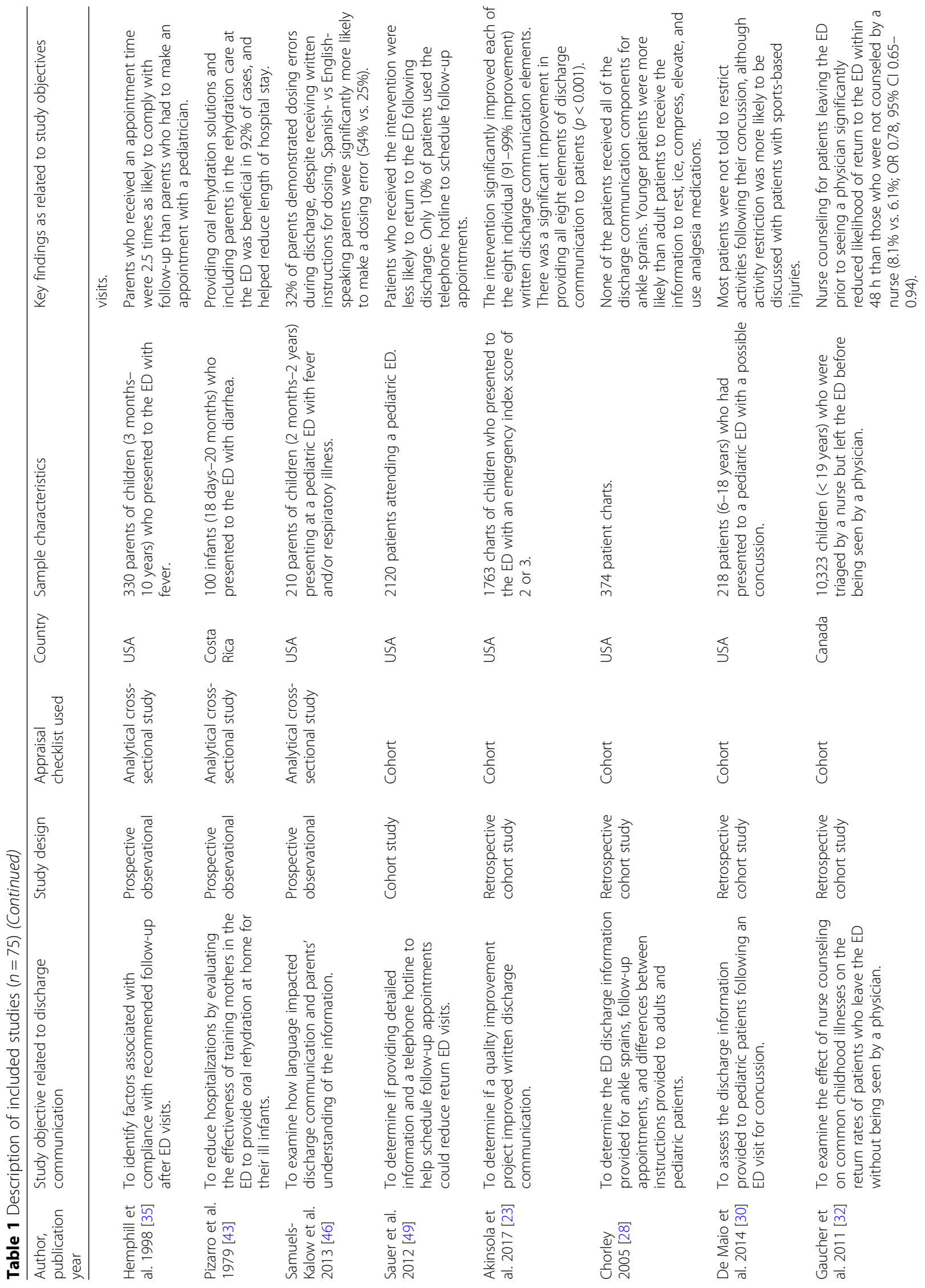


Quran et al. Systematic Reviews

(2019) 8:83

Page 9 of 28

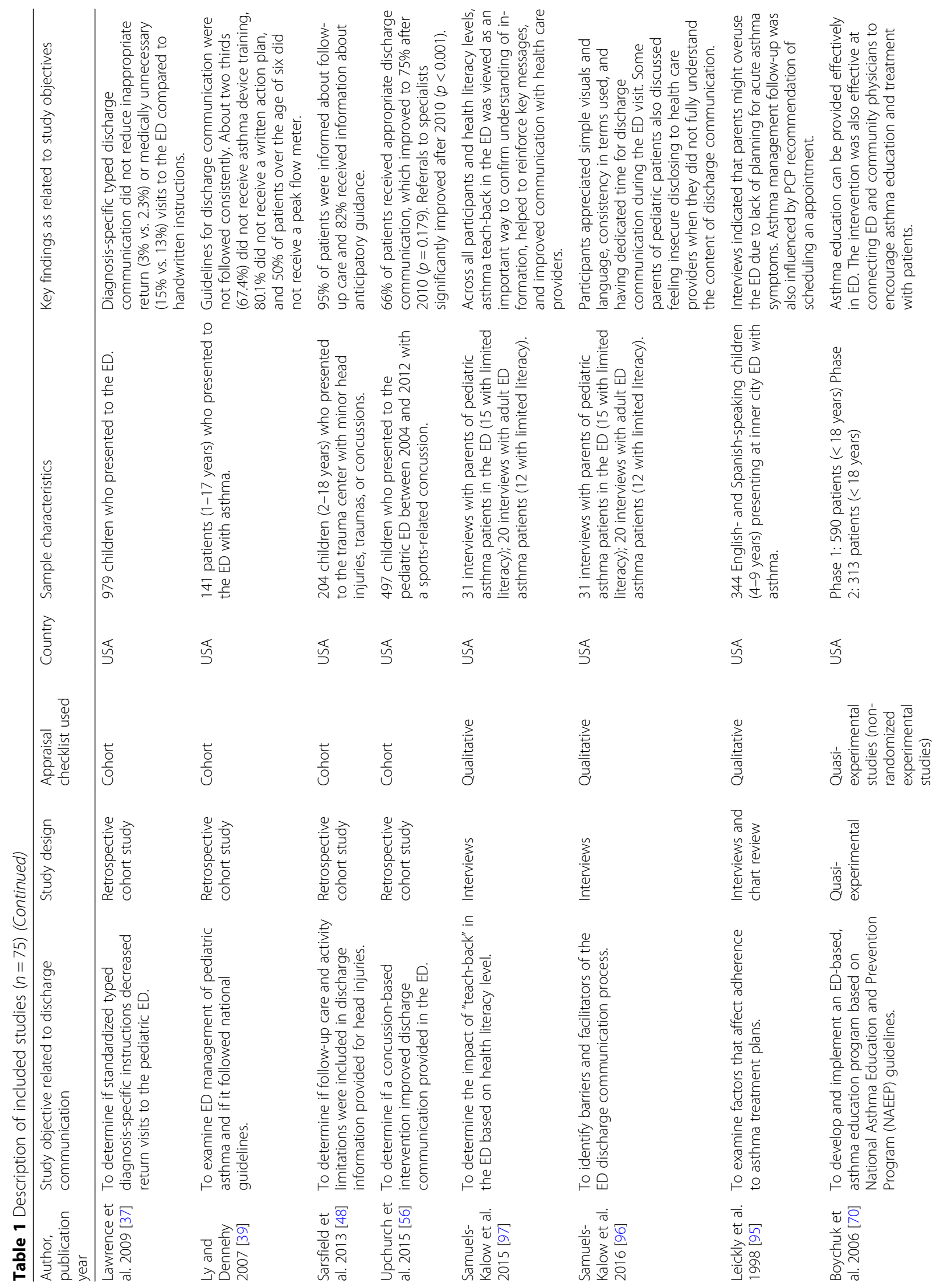




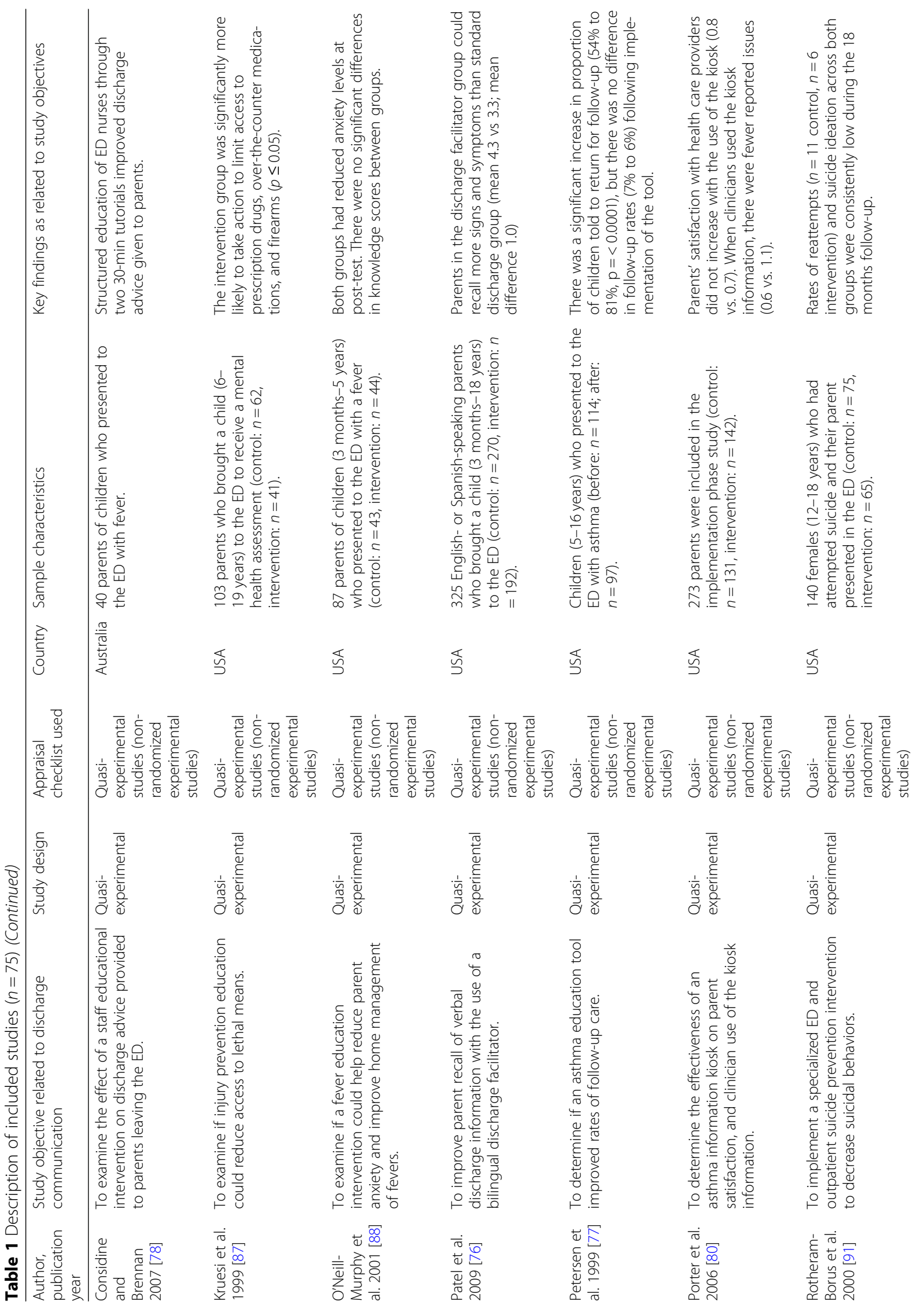




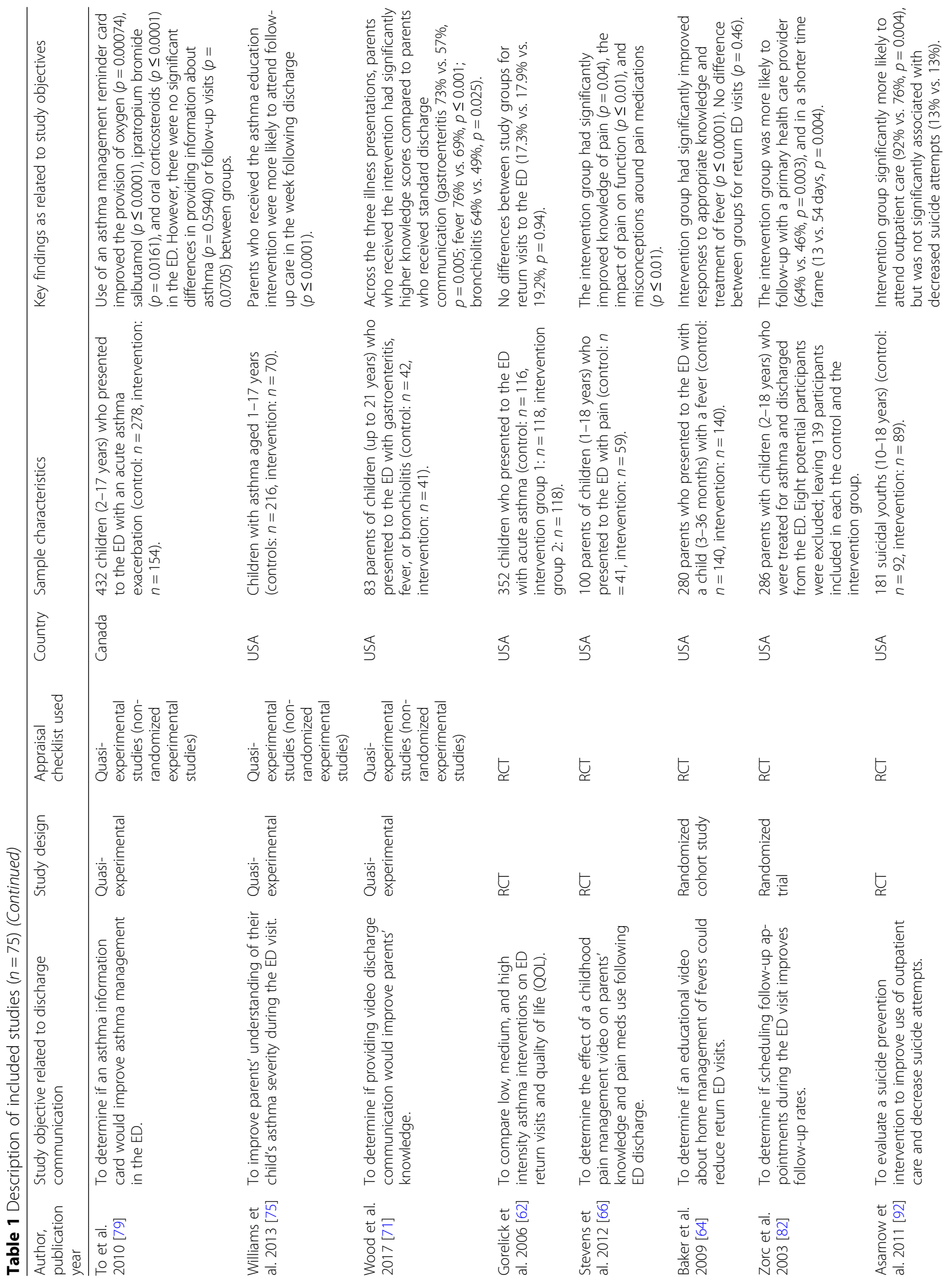




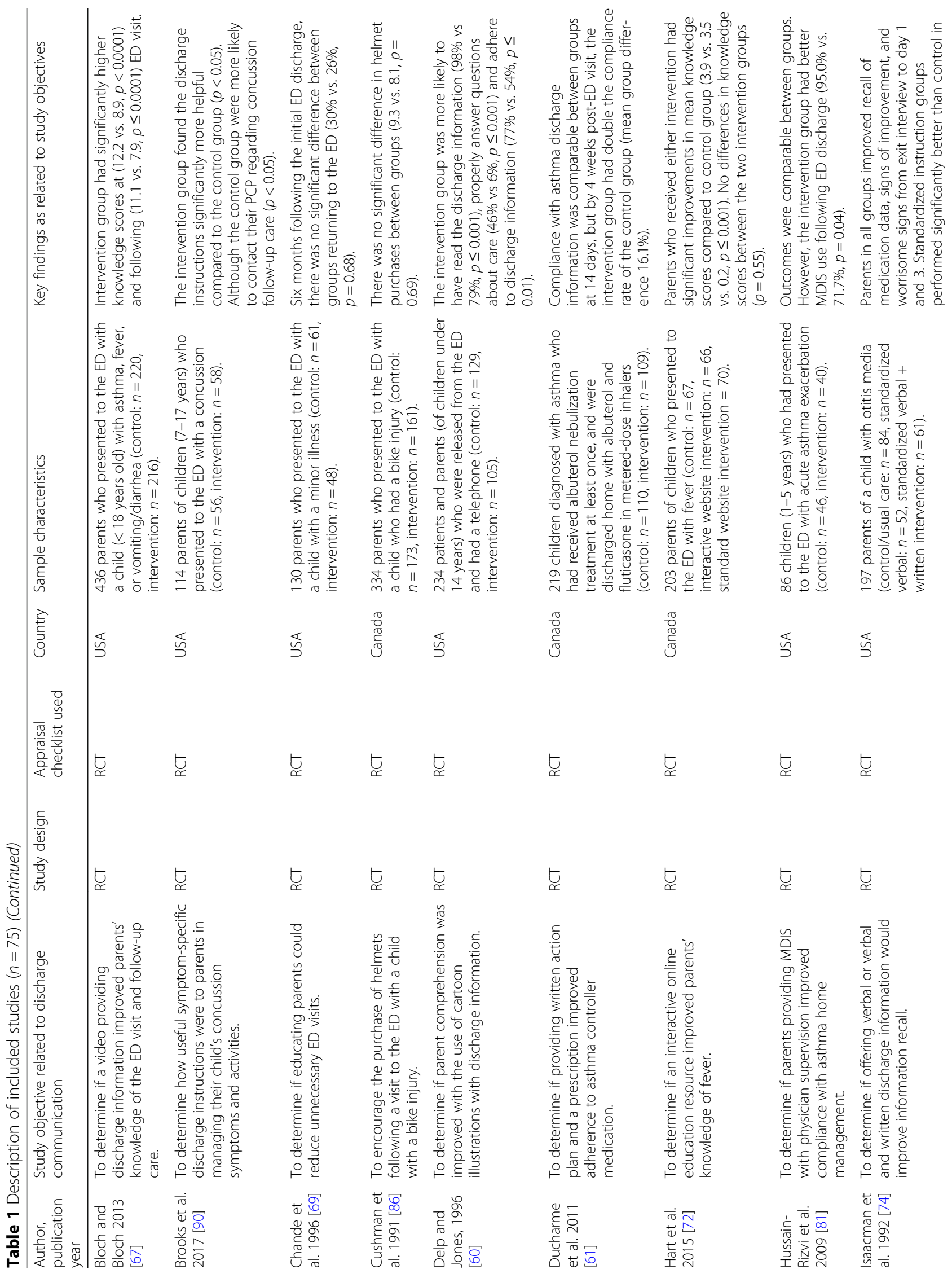




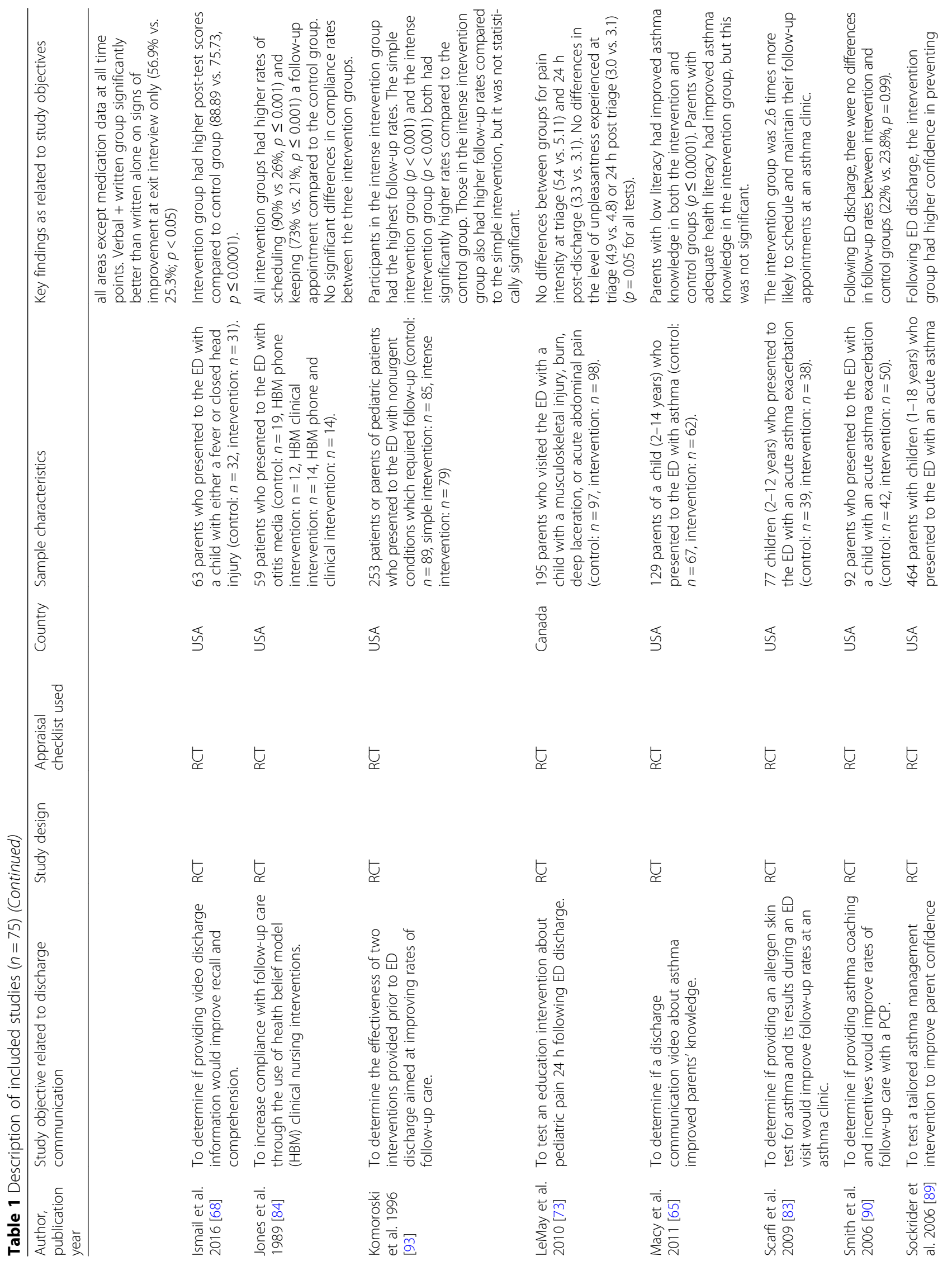


Curran et al. Systematic Reviews

(2019) 8:83

Page 14 of 28

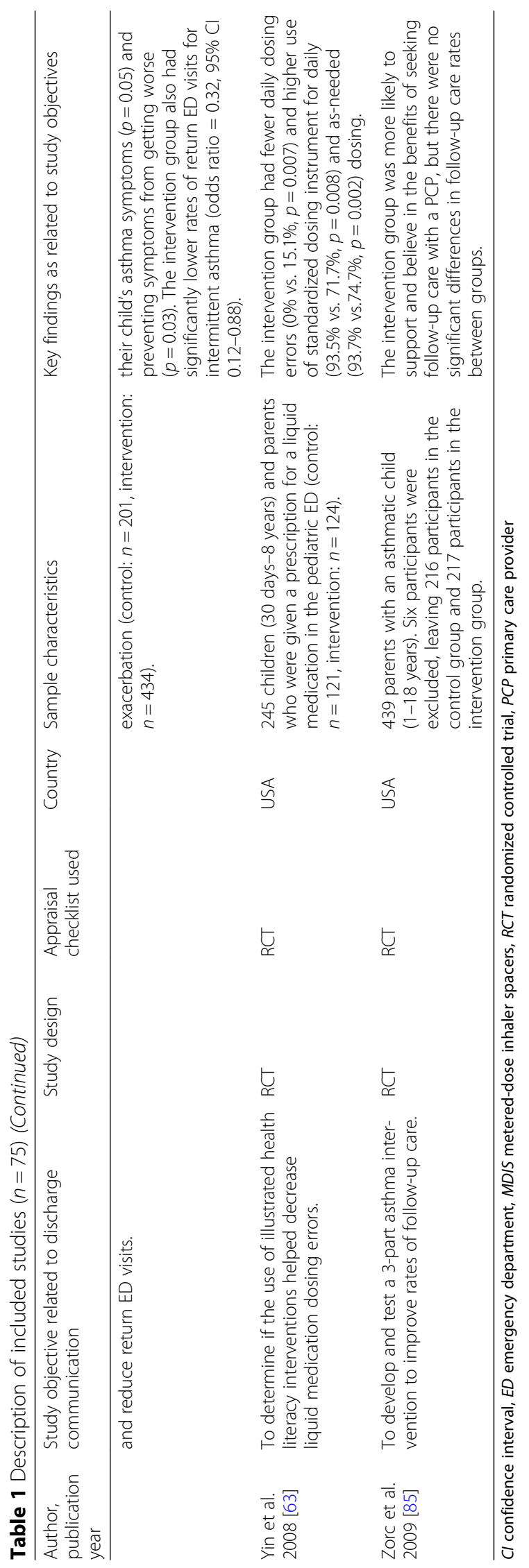




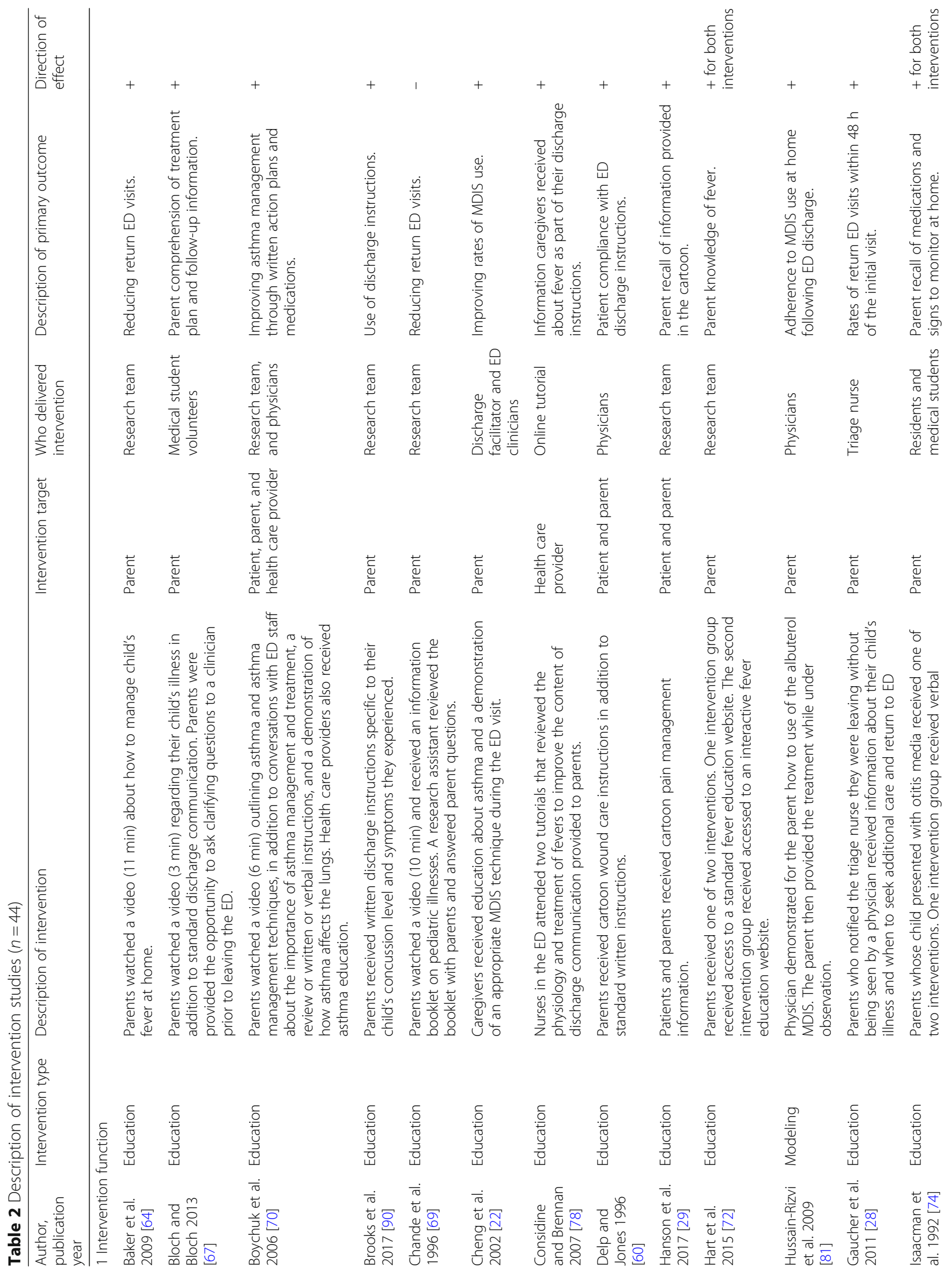




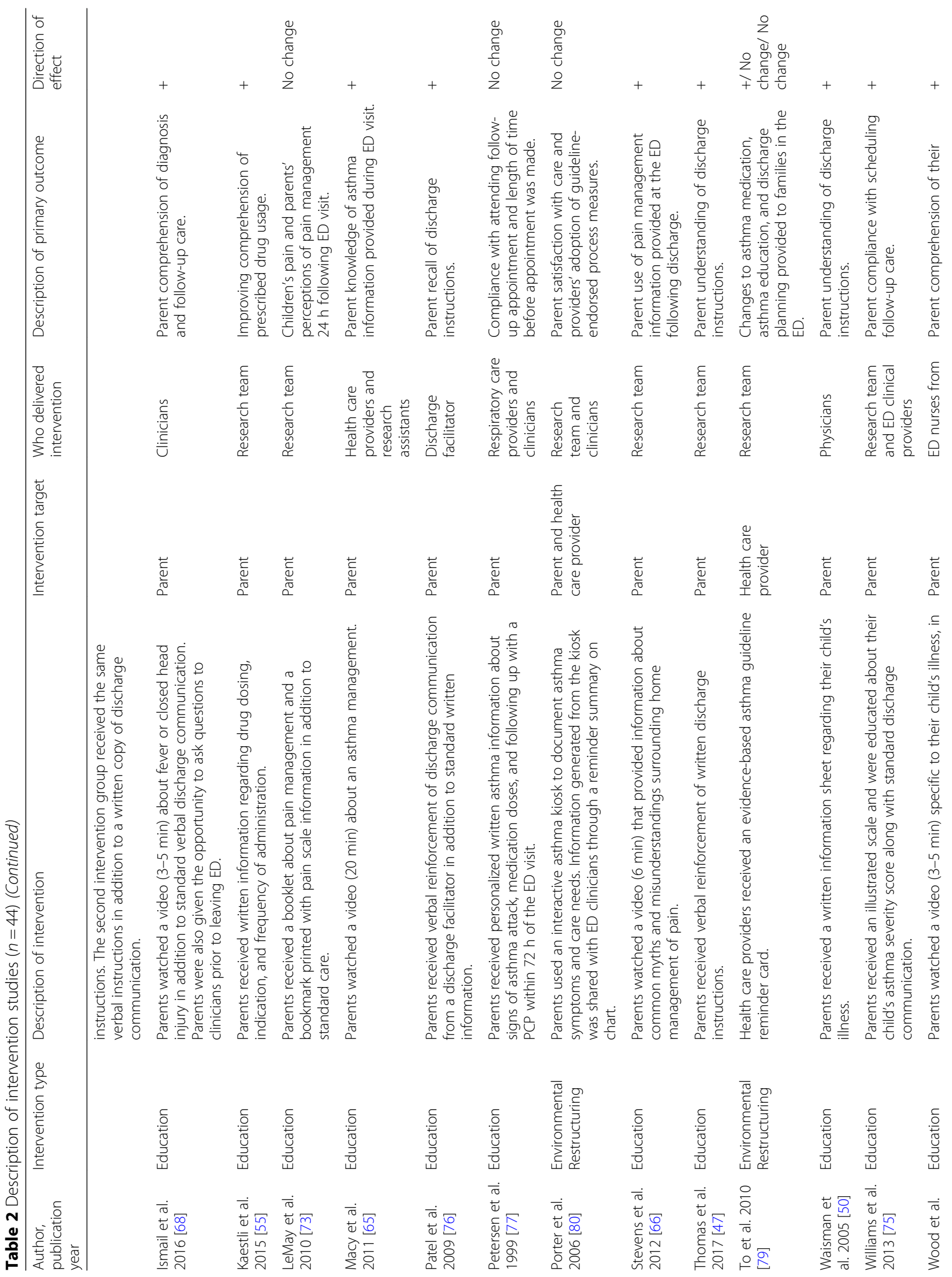




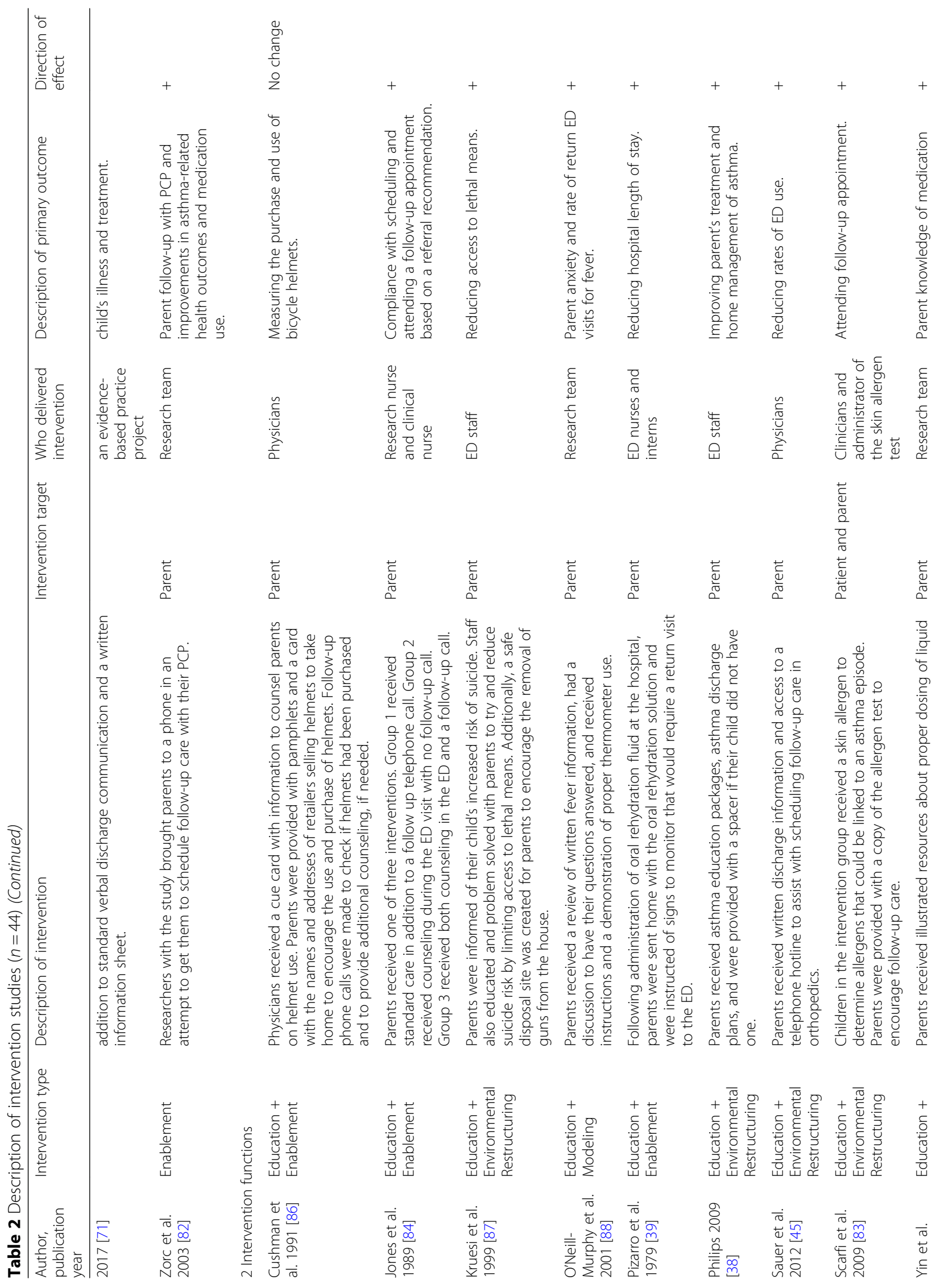




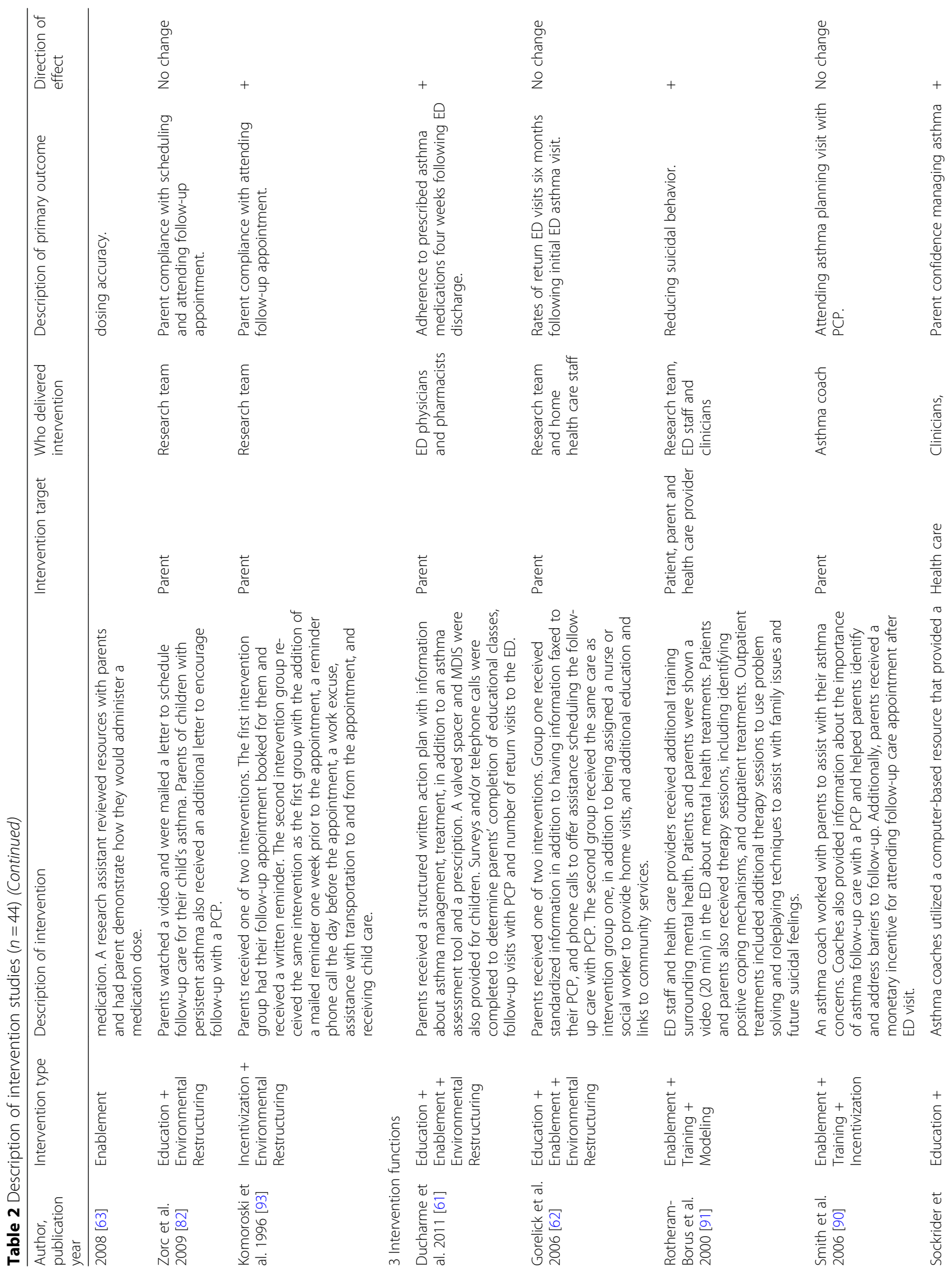




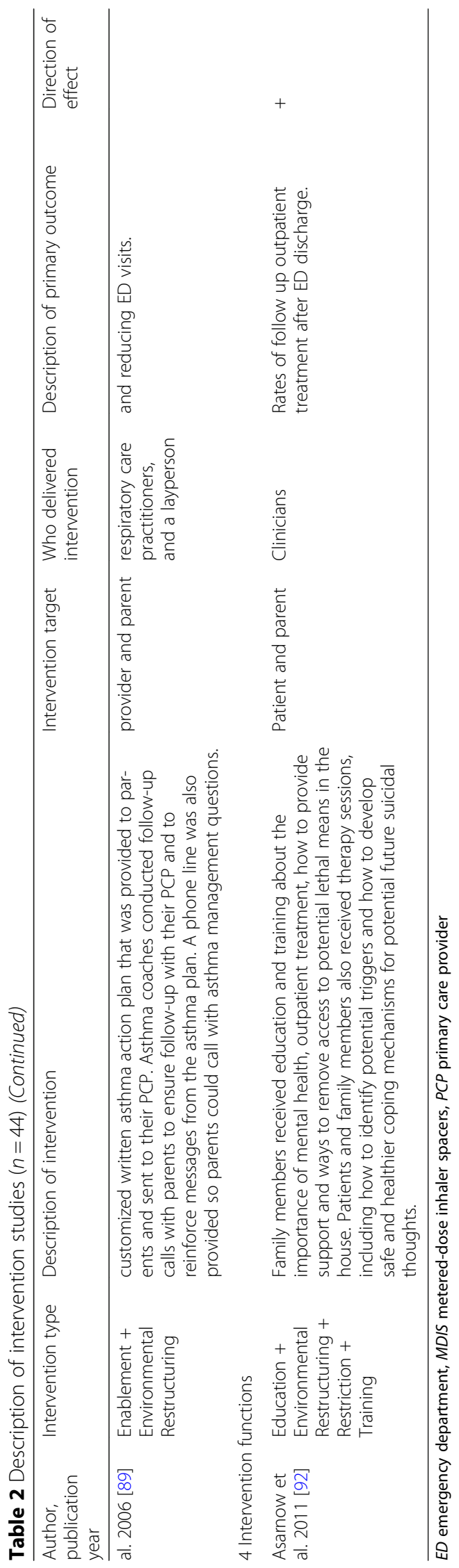


a $10 \%$ difference or more between the study groups. These differences raise some concerns about potential selection bias.

Finally, the three included qualitative studies were assessed using the Checklist for Qualitative Research. Deficits were identified in all studies regarding reporting of the philosophical perspective guiding the study methods and clearly describing the role of the researchers within the studies.

\section{Types of interventions}

We identified 44 discharge communication interventions among the 75 included studies in the review (Table 2). Interventions were comprised of one to four intervention function types, according to the BCW (Table 3) [20]. The heterogeneity of intervention descriptions and outcome measures limited our ability to carry out meta-analysis.

\section{One intervention function type}

The majority of studies (27/44) leveraged a single intervention function type and focused on a range of illness presentations (Table 3). Twenty-three of these involved an education (sharing information) function and primarily focused on evaluating different modes of delivering information about an illness or instructions for managing care at home $[27,32,33,51,54,59,60,64-78$, 94]. Almost half $(10 / 23)$ of these studies examined the use of technology, including video [64-71] or interactive websites [72, 78], as education delivery systems. Technology-enabled tools were used as stand-alone delivery systems [64-67, 72] or enhanced with written and/or face-to-face interaction with staff [68-70]. All studies targeting parents in the ED had a primary goal to increase knowledge [65-68, 71, 72], adherence to guidelines [70], or reduce unnecessary ED return visits [69]. Only one technology-enabled education type intervention targeted healthcare providers and evaluated the effect of two 30-min online tutorials for ED nursing staff focused on physiology and management of fever and febrile convulsions on the discharge advice given to parents [78]. Overall, technology-enabled education type interventions targeting parents had a positive impact on knowledge acquisition and adherence to guidelines, but were not effective in reducing unnecessary return visits to the ED (Table 2).

The remaining education type intervention studies $(13 / 23)$ examined printed discharge communication alone $[73,77,94]$ or with other supports such as cartoons [33, 60], verbal reinforcement of written instructions [51, 54, 59, 74-76], confirming appropriate understanding through observation of parent technique [27], or verbal instructions alone [32]. These studies targeted a range of illness presentations and examined a variety of outcomes including feasibility in the ED, improvement of parent's knowledge, comprehension and/ or recall about specific diagnosis, important signs and symptoms or treatment instructions, and adherence to instructions (including follow-up). Overall direction of effect was positive in most studies examining parent recall of discharge information [33, 51, 76] and knowledge and comprehension $[54,59,60]$ (Table 2).

The four single intervention studies that did not involve education as an intervention function contained environmental restructuring (changing the physical and social context) [79, 80], modeling (providing an example for people to aspire to or imitate) [81], or enablement (increasing the means/reducing barriers to increase capability or opportunity) [82]. Both environmental restructuring interventions targeted healthcare providers, focused on asthma, and included paper-based reminders. There was no significant change in provider behavior in either study (Table 2).

\section{Two intervention function types}

Eleven of the included studies combined two intervention functions in their discharge communication strategy (see Table 2). Again, education was a common intervention function across ten of these studies, with a second intervention function added to either overcome existing barriers (environmental restructuring) [42, 49, 83, 85, 87] or provide additional support to encourage a specific behavior (enablement [43, 63, 84, 86] or modeling [88]). Only one intervention did not include an education component, instead favoring incentivization and environmental restructuring [93]. All two intervention function studies targeted parents or parents/children and were generally focused on either improving care at home or improving adherence with follow-up instructions.

\section{Three intervention function types}

Five studies reported using a combination of three different intervention function types, including education, enablement, environmental restructuring, training, and incentivization [61, 62, 89-91] (Table 2). Four of the studies were focused on improving asthma management following an ED visit and one was focused on improving care provided to adolescent females who attempted suicide and presented to an ED. Three of the four asthma-focused studies used education in combination with enablement and environmental restructuring $[61,62,89]$.

\section{Four intervention function types}

We identified one study that included four intervention functions (Table 3). Asarnow et al. (2011) developed an intervention which included a brief crisis therapy session in the ED and a structured telephone contact for motivating and supporting outpatient treatment within the 
Table 3 Behavior change wheel domains identified in intervention studies $(n=44)$

\begin{tabular}{|c|c|c|c|c|c|c|c|c|}
\hline \multirow[t]{2}{*}{ Authors, publication year } & \multirow{2}{*}{$\begin{array}{l}\text { Illness } \\
\text { presentation }\end{array}$} & \multicolumn{6}{|c|}{ Identified BCW domains } & \multirow{2}{*}{$\begin{array}{l}\text { Direction } \\
\text { of Effect }\end{array}$} \\
\hline & & Education & Incentivization & Training & Enablement & Modeling & $\begin{array}{l}\text { Environmental Restriction } \\
\text { restructuring }\end{array}$ & \\
\hline Baker et al. 2009 [64] & Fever & $\checkmark$ & & & & & & + \\
\hline Bloch and Bloch 2013 [67] & $\begin{array}{l}\text { Asthma, fever, } \\
\text { vomiting, } \\
\text { or diarrhea }\end{array}$ & $\checkmark$ & & & & & & + \\
\hline Boychuk et al. 2006 [70] & Asthma & $\checkmark$ & & & & & & + \\
\hline Brooks et al. 2017 [90] & Concussion & $\checkmark$ & & & & & & + \\
\hline Chande et al. 1996 [69] & Minor illnesses & $\checkmark$ & & & & & & - \\
\hline Cheng et al. 2002 [27] & Asthma & $\checkmark$ & & & & & & + \\
\hline $\begin{array}{l}\text { Considine and Brennan } \\
2007 \text { [78] }\end{array}$ & Fever & $\checkmark$ & & & & & & + \\
\hline Delp and Jones 1996 [60] & Lacerations & $\checkmark$ & & & & & & + \\
\hline Hanson et al. 2017 [33] & $\begin{array}{l}\text { Pain } \\
\text { presentations }\end{array}$ & $\checkmark$ & & & & & & + \\
\hline Hart et al. 2015 [72] & Fever & $\checkmark$ & & & & & & + \\
\hline Gaucher et al. 2011 [32] & Various illnesses & $\checkmark$ & & & & & & + \\
\hline Isaacman et al. 1992 [74] & Otitis media & $\checkmark$ & & & & & & + \\
\hline Ismail et al. 2016 [68] & $\begin{array}{l}\text { Fever and closed } \\
\text { head injury }\end{array}$ & $\checkmark$ & & & & & & + \\
\hline Kaestli et al. 2015 [59] & $\begin{array}{l}\text { Illnesses requiring } \\
\text { prescription }\end{array}$ & $\checkmark$ & & & & & & + \\
\hline LeMay et al. 2010 [73] & Various injuries & $\checkmark$ & & & & & & No change \\
\hline Macy et al. 2011 [65] & Asthma & $\checkmark$ & & & & & & + \\
\hline Patel et al. 2009 [76] & Gastroenteritis & $\checkmark$ & & & & & & + \\
\hline Petersen et al. 1999 [77] & Asthma & $\checkmark$ & & & & & & No change \\
\hline Stevens et al. 2012 [66] & Pediatric pain & $\checkmark$ & & & & & & + \\
\hline Thomas et al. 2017 [51] & $\begin{array}{l}\text { Mild traumatic } \\
\text { brain injuries }\end{array}$ & $\checkmark$ & & & & & & + \\
\hline Waisman et al. 2005 [54] & Various illnesses & $\checkmark$ & & & & & & + \\
\hline Williams et al. 2013 [75] & Asthma & $\checkmark$ & & & & & & + \\
\hline Wood et al. 2017 [71] & $\begin{array}{l}\text { Gastroenteritis, } \\
\text { bronchiolitis, } \\
\text { and fever }\end{array}$ & $\checkmark$ & & & & & & + \\
\hline Zorc et al. 2003 [82] & Asthma & & & & $\checkmark$ & & & + \\
\hline $\begin{array}{l}\text { Hussain-Rizvi } \\
\text { et al. } 2009 \text { [81] }\end{array}$ & Asthma & & & & & $\checkmark$ & & + \\
\hline Porter et al. 2006 [80] & Asthma & & & & & & $\checkmark$ & No change \\
\hline To et al. 2010 [79] & Asthma & & & & & & $\checkmark$ & $\begin{array}{l}\text { +/No change/ } \\
\text { No change }\end{array}$ \\
\hline Cushman et al. 1991 [86] & Bike injury & $\checkmark$ & & & $\checkmark$ & & & No change \\
\hline Jones et al. 1989 [84] & Otitis media & $\checkmark$ & & & $\checkmark$ & & & + \\
\hline Pizarro et al. 1979 [43] & Diarrhea & $\checkmark$ & & & $\checkmark$ & & & + \\
\hline Yin et al. 2008 [63] & Various illnesses & $\checkmark$ & & & $\checkmark$ & & & + \\
\hline Kruesi et al. 1999 [87] & Mental health & $\checkmark$ & & & & & $\checkmark$ & + \\
\hline Phillips 2009 [42] & Asthma & $\checkmark$ & & & & & $\checkmark$ & + \\
\hline Sauer et al. 2012 [49] & Fractures & $\checkmark$ & & & & & $\checkmark$ & + \\
\hline Scarfi et al. 2009 [83] & Asthma & $\checkmark$ & & & & & $\checkmark$ & + \\
\hline
\end{tabular}


Table 3 Behavior change wheel domains identified in intervention studies $(n=44)$ (Continued)

\begin{tabular}{|c|c|c|c|c|c|c|c|c|c|}
\hline \multirow[t]{2}{*}{ Authors, publication year } & \multirow{2}{*}{$\begin{array}{l}\text { Illness } \\
\text { presentation }\end{array}$} & \multicolumn{7}{|c|}{ Identified BCW domains } & \multirow{2}{*}{$\begin{array}{l}\text { Direction } \\
\text { of Effect }\end{array}$} \\
\hline & & Education & Incentivization & Training & Enablement & Modeling & $\begin{array}{l}\text { Environmental } \\
\text { restructuring }\end{array}$ & Restriction & \\
\hline Zorc et al. 2009 [85] & Asthma & $\checkmark$ & & & & & $\checkmark$ & & No change \\
\hline $\begin{array}{l}\text { O'Neill-Murphy } \\
\text { et al. } 2001 \text { [88] }\end{array}$ & Fever & $\checkmark$ & & & & $\checkmark$ & & & + \\
\hline $\begin{array}{l}\text { Komoroski et al. } 1996 \\
\text { [93] }\end{array}$ & $\begin{array}{l}\text { Minor, acute } \\
\text { infections }\end{array}$ & & $\checkmark$ & & & & $\checkmark$ & & + \\
\hline $\begin{array}{l}\text { Ducharme et al. } 2011 \\
\text { [61] }\end{array}$ & Asthma & $\checkmark$ & & & $\checkmark$ & & $\checkmark$ & & + \\
\hline Gorelick et al. 2006 [62] & Asthma & $\checkmark$ & & & $\checkmark$ & & $\checkmark$ & & No change \\
\hline Sockrider et al. 2006 [89] & Asthma & $\checkmark$ & & & $\checkmark$ & & $\checkmark$ & & + \\
\hline Smith et al. 2006 [90] & Asthma & & $\checkmark$ & $\checkmark$ & $\checkmark$ & & & & No change \\
\hline $\begin{array}{l}\text { Rotheram-Borus } \\
\text { et al. } 2000 \text { [91] }\end{array}$ & Mental health & & & $\checkmark$ & $\checkmark$ & $\checkmark$ & & & + \\
\hline Asarnow et al. 2011 [92] & Mental health & $\checkmark$ & & $\checkmark$ & & & $\checkmark$ & $\checkmark$ & + \\
\hline
\end{tabular}

first $48 \mathrm{~h}$ after the ED visit. We noted this intervention involved education, environmental restructuring, restriction, and training to improve follow-up rates of youth experiencing suicidality treated in an ED [92].

\section{Implementation strategies}

The majority of interventions were delivered to children and parents by clinicians $[27,32,42,43,49,54,60,61$, $67,68,71,74,76,77,81,83,86,87,89,90,92]$. Various clinicians were involved in the implementation of interventions including ED clinicians $[27,42,49,54,60,61$, $65,68,75,80,81,83,86,87,92]$, medical students/residents $[67,74]$, primary care providers (PCP) $[82,85]$, nurses [32, 43, 71, 84], pharmacists [61], and respiratory therapists [77]. Additionally, one study utilized a discharge facilitator to provide specific discharge communication to parents for gastroenteritis [76].

Most studies provided few details about the timing of intervention implementation, typically referencing that it was provided during the ED stay $[60,61,63,64,66-68$, $73,74,76,80-92]$. Thus, it was difficult to determine the exact point during the care process the intervention was delivered and the duration of the intervention. When specific timing of the interventions was indicated, it was either described as at the time of discharge [63], upon ED admission [77], directly following triage [65], or after the child was evaluated by an ED physician [69].

\section{Conceptual mapping}

Conceptual mapping is a useful technique for exploring relationships in the data of narrative synthesis [98]. Using a consensus approach, three members of the research team reviewed the narrative summaries of all included studies during two half-day meetings and identified several key concepts and relevant terms to describe how discharge communication worked or did not work for children and their parents in ED settings (Fig. 2). The final schematic depicts the key barriers and enablers for discharge communication across all included studies. Key concepts include ED context, knowledge, attitudes and beliefs, ED healthcare providers, child and parents, intervention, education, and outcomes. Important linking terms include health literacy, timing, illness severity, readiness to learn, rapport, and training.

Barriers and enablers to successful discharge communication were identified at a number of levels, including the intervention, healthcare providers, child/parent, and the context in which care is delivered. The majority of interventions targeted parents and included education as a core strategy. Although not explicitly stated, the educational interventions in the studies appear to operate on the assumption that imparting information will improve health care provider or parent knowledge and subsequently change behaviors. Few studies used theory to guide design of the intervention $[71,80,81,83,84,89$, 90, 95], and there was no formal assessment of potential barriers to changing parent, child, or health care provider behaviors. This made it difficult to understand how the interventions were expected to improve outcomes. Barriers related to intervention design (language, literacy level, content, readability) and delivery (timing during the visit, duration, fidelity, mode, extent of interactivity) were identified as important factors across a number of studies $[26,55,57,60,65-67,74,78,84,86$, $89,99]$. While there was variation in who delivered the interventions, it is important to highlight that in a number of the experimental trials, the interventions were delivered by individuals who were not regular members of the ED team $[33,51,59,63,64,66,69,70,72,73,79,82$, $85,88]$. A collaborative approach to co-designing 


\section{Concept Map: Discharge Communication in Pediatric EDs}

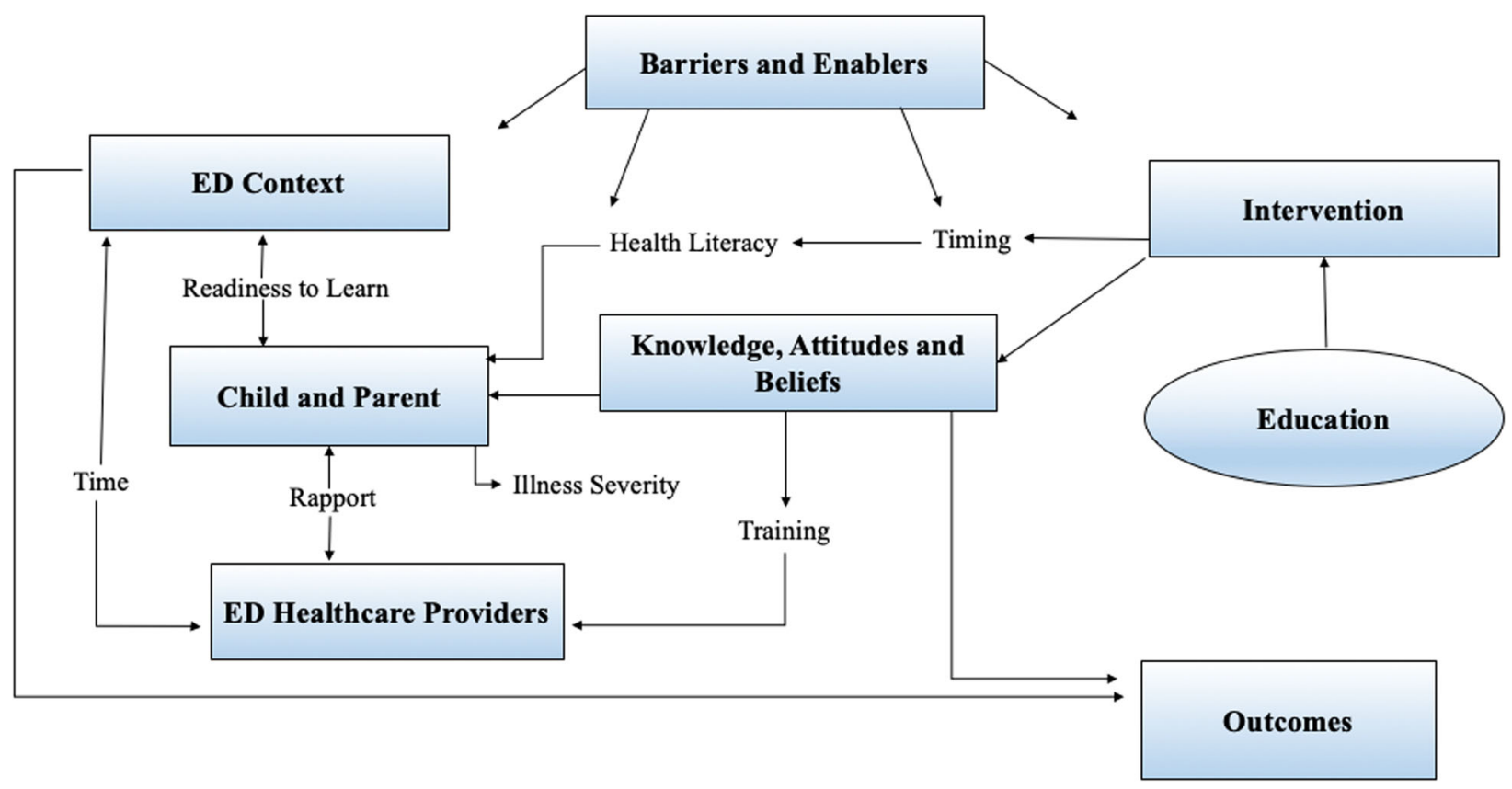

Fig. 2 Concept Map

interventions was proposed by some authors as a possible strategy to enhance implementation [33, 40, 49, 70].

A number of barriers and enablers related to the patient and parent were reported including complexity of the patient presentation $[53,57,69,75,84]$, first language and health literacy $[35,42,46,52]$, expectations of care [25], and past experience $[66,71]$. Parents' health literacy was considered an important factor in both the design [54, 63, 67] and the mode of delivery $[46,50,57,65]$ of the intervention. Parental stress was also considered an important influence on parents' readiness to engage in discharge communication [26, 53, 69]. Actively engaging parents in the discharge process throughout their ED visit $[27,78,81]$ and presenting information using multiple delivery modes $[33,51,68,75,80,83,96]$ were thought to be important enablers. Parent decision making about the nuances of follow-up care post discharge can be complex [94]. It was also recognized that parents leverage a number of external knowledge sources including family and non-healthcare workers when making decisions about care for their child at home following an ED visit [52, 64, 65, 97].

Several studies suggested that ED healthcare providers recognize discharge communication as an important aspect of their everyday professional practice for both clinical and medicolegal reasons [23, 32], but there appears to be a fuzzy boundary between patient education and the provision of discharge information [70]. Discharge communication practice variation was common across a number of studies $[30,31,100]$. Healthcare provider training [23, 27, 28, 55, 74, 77, 86], beliefs and attitudes about discharge communication [40, 41, 57], and limited use of medical jargon $[53,96]$ were identified as important factors influencing success. Rapport between healthcare providers and parents was also considered an important factor contributing to successful discharge communication $[69,81,95]$. Although we did not identify any interventions that focused specifically on building rapport between providers and parents, the quality of the interaction between providers and patients/parents was highly valued as contributing to successful discharge communication [34, 46, 60, 69, 76, 81, 84, 88, 97].

The context of the ED including factors related to managing multiple patients in a compressed period of time and emphasis on patient flow can pose unique barriers to discharge communication [30, 55, 92]. Approaches to address some of these contextual barriers include a dedicated space for teaching, easily accessible resources, and the inclusion of strategies that reduce the time burden on ED providers and can easily be incorporated into the busy workflow of the ED $[55,79,80,86,96]$. However, Macy et al. (2011) noted that even the use of video education can be hindered during times of high patient volumes [65]. Ideal structures support discharge communication that is consistent and comprehensive yet succinct and relevant $[23,44,97]$. ED team practice norms regarding discharge communication $[42,78]$ and roles in the ED specifically dedicated to discharge communication may assist with consistent and reliable delivery $[27,39,76]$. 
Although there was wide variation in primary outcomes across studies, parent knowledge, comprehension, and recall were deemed important outcomes in a number of studies [33, 51, 59, 63, 65, 67, 68, 70-72]. Unfortunately, there was little consistency in how knowledge, comprehension, and recall were measured across these studies.

\section{Policies guiding pediatric discharge communication}

We received a total of 36 responses to our email surveys $($ Canada $=17$; Australia $=13$, USA $=6)$ with no relevant pediatric ED discharge communication policies or guidelines identified. Following our search of the gray literature, three documents were discovered that included either policies or guidelines regarding the provision of discharge communication [101]. A joint policy developed by the American Academy of Pediatrics and the Committee on Pediatric Emergency Medicine recommended the provision of discharge communication within a familycentered care approach, [101]. Generally, this guideline contained very little direction in the way of discharge content and processes, and it is unclear if it translates into active policy development [101]. The Scottish Intercollegiate Guidelines Network (SIGN) has produced a generic discharge document tool that can be implemented to guide the discharge process [102]. The discharge document provides guidance on important content that should be communicated at discharge, including primary discharge diagnosis, presenting complaint, significant procedures, new medications, and follow-up instructions [102]. However, no specific recommendations are made about how the SIGN discharge document should be generated, updated, and used in ED clinical practice [102]. Finally, the National Guidelines Clearinghouse contained one active policy that is currently utilized by affiliated children's hospitals in the USA. This policy outlines standards for discharge communication as the primary responsibility of the ED nurse and that all patients are to be discharged home with explicit plans for follow-up care, a summary of the visit, appropriate instructions for care, and prescription medications [103]. Prior to discharge, it is the responsibility of the nurse to verify that all health care concerns have been addressed, parents are aware of when to return to the ED, documentation is complete, and medications have been reviewed with the patient [103].

\section{Discussion}

The body of literature exploring discharge communication in a pediatric ED context is highly heterogeneous, reporting a range of interventions, delivery methods, and outcome measures across a variety of illness presentations. These findings are consistent with systematic reviews of discharge communication practices in hospital settings [15, 104]. In general, our findings demonstrate that discharge communication in pediatric emergency practice environments has been largely oversimplified with a corresponding atheoretical approach to intervention design, involving strategies that ignore the context of where the communication takes place (ED) and where the information is primarily used by the parents (home). Education was the most common type of intervention evaluated. The underlying assumption appears to be that a parent's lack of knowledge is the most important contributor to poor child outcomes and educational interventions are the most viable solution. We noted a lack of focus on child and youth comprehension and limited attention on healthcare provider knowledge and skills to deliver discharge communication. However, through a concept mapping exercise, we were able to identify factors at the individual, intervention, and system level that may affect successful discharge communication in a pediatric emergency care context.

Many of the educational interventions included in our review relied on passive dissemination strategies to deliver information. Yet, we know that behavior change requires more than simply the acquisition of knowledge [105]. Passive dissemination of educational material is rarely effective in changing the behavior of providers or improving patient outcomes [106, 107]. Adults learn best when there is a perceived need, active participation, reinforcement of new behaviors, and immediate feedback and correction of misconceptions [108, 109]. Active engagement in learning such as the use of teach-back strategies have been associated with improved comprehension, more patient-centered communication, and increased engagement of parents [110-112]. Teach-back is a way of checking comprehension by asking patients to repeat back in their own words what they have been told by their health care provider [113]. However, further research is needed regarding the efficacy, feasibility, fidelity and acceptability of teach-back in an ED setting [112]. The use of behavior change theories to specify behavioral targets and guide intervention design in future discharge communication studies are needed to strengthen this body of literature and assist with identifying and evaluating the "active ingredients" that affect intervention outcomes [114].

While standardizing discharge communication may be viewed as one way of achieving good quality discharge communication, our synthesis demonstrated conflicting results pertaining to the effectiveness of standardized discharge communication. Standardized instructions are often recommended to increase familiarity with ED discharge documentation for patients, staff, and general practitioners [115]. One study in this synthesis showed improved communication of important discharge information through the use of standardized discharge communication in children with otitis media [84]. However, other authors reported that standardized instructions were 
insufficient to enhance adherence and comprehension [50]. In light of this, ensuring that discharge instructions contain common elements, while still allowing for adaptation and tailoring to accommodate provider and parent needs, might be a more appropriate approach.

Finally, our findings reveal a dearth of existing policies guiding discharge communication practice in a Canadian pediatric ED context. Further, there appears to be a lack of clarity regarding professional accountability for discharge communication in the literature. Tavender et al. (2014) examined factors that influence management of mild traumatic brain injury in the ED. They noted that physicians felt primarily responsible for discharge communication as they were the health care provider responsible for discharging a patient; however, nurses felt discharge communication should be a shared responsibility to ensure patients were adequately educated prior to being sent home [116]. Many of the studies included in our review, particularly those related to asthma [79], recognized the importance of an interdisciplinary approach to discharge communication. Clear guidelines and polices regarding discharge communication practice are critical to ensure more sustainable and reliable discharge communication strategies in the future.

\section{Strengths and limitations}

This review followed established review methodologies including a comprehensive search of the published and gray literature, assessment of risk of bias, and established narrative synthesis strategies to explore relationships across a range of study designs. We incorporated an iKT approach to ensure our findings were relevant to stakeholder needs.

Due to the heterogeneity of the interventions and outcomes, we were unable to perform a meta-analysis. While we used an established behavioral framework to guide our examination of discharge communication interventions, our classification of the included interventions was limited to the details provided in the study reports. It is possible that the interventions contained additional functions that were not captured in our analysis because they were not reported by the study author.

\section{Conclusion}

Improving discharge communication for parents in an ED setting presents a significant opportunity for improving health outcomes for children. The majority of existing strategies to improve discharge communication have been educational strategies targeting parents. Furthermore, theory-based interventions are rare, making it difficult to discern the active ingredients underlying successful interventions. Findings from this review highlight a number of opportunities for ED researchers, clinicians, administrators, and decision-makers to consider strengthening discharge communication policies and improve the design of discharge communication interventions. Effective discharge communication strategies in a pediatric emergency practice context can improve parent comprehension, increase adherence to treatment plans, reduce unnecessary return visits, optimizing health system use, and improving health outcomes for children.

\section{Additional files}

Additional file 1: Search Strategy Terms. (PDF 55 kb)

Additional file 2: Inclusion and Exclusion Criteria. (ZIP 38 kb)

Additional file 3: List of Excluded Studies. (XLS 95 kb)

\section{Abbreviations}

ARCHE: Alberta Research Centre for Child Health Evidence; BCW: Behavior

Change Wheel; Cl: Confidence interval; ED: Emergency department;

HBM: Health belief model; iKT: Integrated knowledge translation; JBI: Joanna

Briggs Institute; MDIS: Metered-Dose Inhaler Spacers; NAEEP: National

Asthma Education and Prevention Program; PCP: Primary care provider;

PECARN: Pediatric Emergency Care Applied Research Network; PEM-

CRC: Pediatric Emergency Medicine Collaborative Research Committee; PERC: Pediatric Emergency Research Canada; PERUKI: Pediatric Emergency Research in the United Kingdom \& Ireland; PREDICT: Pediatric Research in Emergency Departments International Collaborative; RCT: Randomized controlled trial; SIGN: Scottish Intercollegiate Guidelines Network

\section{Acknowledgements}

Ms. Robin Parker, Information Services Librarian, W.K. Kellogg Health Sciences Library, Dalhousie University, and Ms. Megan Bourque, Research Assistant, Dalhousie University.

\section{Funding}

This work was funded by a Canadian Institutes of Health Research- Knowledge Synthesis grant.

\section{Availability of data and materials}

The dataset supporting the conclusions of this article are included within the articles and additional files.

\section{Authors' contributions}

JAC conceived of the study. $\mathrm{KM}, \mathrm{MB}, \mathrm{JAC}$, and $\mathrm{AG}$ participated in data extraction. JAC, AG, KM, AM, AN, JC, MJ, LH, RZ, SC, SM, and AP assisted with data analysis. $J A C, A G$, and $A B$ drafted the manuscript and JAC, $A G, R Z, A N, M J, J C, A M$, and $L H$ made significant contributions to the revising and finalizing the manuscript. All authors read and approved the final manuscript.

Ethics approval and consent to participate

Not applicable.

Consent for publication

Not applicable.

Competing interests

The authors declare that they have no competing interests.

\section{Publisher's Note}

Springer Nature remains neutral with regard to jurisdictional claims in published maps and institutional affiliations.

\section{Author details}

'School of Nursing, Dalhousie University, 5869 University Ave., PO Box 15000, Halifax, NS B3H 4R2, Canada. ${ }^{2}$ Department of Pediatrics, Division of Emergency Medicine, Children's Hospital of Eastern Ontario, 401 Smyth Rd, Ottawa, ON K1H 8L1, Canada. ${ }^{3}$ Department of Pediatrics, Faculty of Medicine \& Dentistry, University of Alberta, 11405-87 Avenue, Edmonton, AB T6G 1C9, 
Canada. IIWK Health Center, 5850/5980 University Avenue, PO Box 9700, Halifax, NS B3K 6R8, Canada. ${ }^{5}$ College of Pharmacy, Dalhousie University, 5869 University Avenue, PO Box 15000, Halifax, NS B3H 4R2, Canada. ${ }^{6}$ Charles V. Keating Emergency and Trauma Centre, QEll Health Sciences Centre, 1796 Summer St, Halifax, NS B3H 3A7, Canada.

\section{Received: 30 December 2018 Accepted: 22 March 2019}

Published online: 03 April 2019

\section{References}

1. Canadian Institute of Health Information. Sources of potentially avoidable emergency department visits. 2014. https:/secure.cihi.ca/free_products/ED_ Report_ForWeb_EN_Final.pdf.

2. Canadian Institute for Health Information. Understanding Emergency Department Wait Times. 2007. https://secure.cihi.ca/free_products/ Emergency_Department_Wait_Times_III_2007_e.pdf. Accessed 14 Mar 2017.

3. Makaryus AN, Friedman EA. Patients' understanding of their treatment plans and diagnosis at discharge. Mayo Clin Proc. 2005;80:991-4.

4. Engel $\mathrm{KG}$, Heisler M, Smith DM, Robinson $\mathrm{CH}$, Forman JH, Ubel PA. Patient comprehension of emergency department care and instructions: are patients aware of when they do not understand? Ann Emerg Med. 2009;53:454-461.e15.

5. Heng KWJ, Tham KY, How KY, Foo JS, Lau YH, Li AYK. Recall of discharge advice given to patients with minor head injury presenting to a Singapore emergency department. Singap Med J. 2007:48:1107-10.

6. Samuels-Kalow ME, Stack AM, Porter SC. Effective discharge communication in the emergency department. Ann Emerg Med. 2012;60:152-9.

7. Kuan WS, Mahadevan M. Emergency unscheduled returns: can we do better? Singap Med J. 2009;50:1068-71.

8. $\mathrm{Ng} \mathrm{C}$, Chung C. An analysis of unscheduled return visits to the accident and emergency department of a general public hospital. Hong Kong J Emerg Med. 2003;10:153-61.

9. Vashi A, Rhodes KV. "Sign right here and you're good to go": a content analysis of audiotaped emergency department discharge instructions. Ann Emerg Med. 2011;57:315-322.e1.

10. Nobile C, Drotar D. Research on the quality of parent-provider communication in pediatric care: implications and recommendations. J Dev Behav Pediatr. 2003:24:279-90.

11. Jolly BT, Scott JL, Sanford SM. Simplification of emergency department discharge instructions improves patient comprehension. Ann Emerg Med. 1995;26:443-6.

12. Parikh NS, Parker RM, Nurss JR, Baker DW, Williams MV. Shame and health literacy: the unspoken connection. Patient Educ Couns. 1996;27:33-9.

13. Schillinger D, Grumbach K, Piette J, Wang F, Osmond D, Daher C, et al. Association of health literacy with diabetes outcomes. JAMA. 2002;288: 475-82.

14. Sevick LK, Esmail R, Tang K, Lorenzetti DL, Ronksley P, James M, et al. A systematic review of the cost and cost-effectiveness of electronic discharge communications. BMJ Open. 2017;7:e014722.

15. Glick AF, Farkas JS, Nicholson J, Dreyer BP, Fears M, Bandera C, et al. Parental management of discharge instructions: a systematic review. Pediatrics. 2017;140:e20164165.

16. Popay J, Roberts H, Sowden A, Petticrew M, Arai L, Rodgers M, et al. Guidance on the conduct of narrative synthesis in systematic reviews: a product from the ESRC methods Programme. 2006. https://www. researchgate.net/publication/233866356_Guidance_on_the_conduct_of_ narrative_synthesis in_systematic reviews_A product from_the_ESRC Methods_Programme. Accessed 22 Dec 2017.

17. Lucas PJ, Baird J, Arai L, Law C, Roberts HM. Worked examples of alternative methods for the synthesis of qualitative and quantitative research in systematic reviews. BMC Med Res Methodol. 2007;7:4.

18. Barnett-Page E, Thomas J. Methods for the synthesis of qualitative research: a critical review. BMC Med Res Methodol. 2009;9:59.

19. Curran JA, Murphy A, Newton M, Zemek R, Hartling L, Plint A, et al. Discharge instructions for caregivers in the context of pediatric emergency care: a narrative synthesis protocol. Syst Rev. 2014;3:26.

20. Michie $S$, Atkins $L$, West R. The behaviour change wheel: a guide to designing interventions. 1st ed. Great Britain: Silverback Publishing; 2014

21. NVivo qualitative data analysis Software. QSR International Pty Ltd; 2014.

22. Critical Appraisal Tools - JBI. http://joannabriggs.org/research/criticalappraisal-tools.html. Accessed 22 Dec 2017.
23. Akinsola B, Cheng J, Zmitrovich A, Khan N, Jain S. Improving discharge instructions in a pediatric emergency department: impact of a quality initiative. Pediatr Emerg Care. 2017;33:10-3.

24. Al-Harthy N, Sudersanadas KM, Al-Mutairi M, Vasudevan S, Bin Saleh G, AlMutairi M, et al. Efficacy of patient discharge instructions: a pointer toward caregiver friendly communication methods from pediatric emergency personnel. J Fam Community Med. 2016;23:155-60.

25. Ali AB, Place R, Howell J, Malubay SM. Early pediatric emergency department return visits: a prospective patient-centric assessment. Clin Pediatr (Phila). 2012;51:651-8.

26. Chacon D, Kissoon NM, Rich S. Education attainment level of caregivers versus readability level of written instructions in a pediatric emergency department. Pediatr Emerg Care. 1994; 10:144-9.

27. Cheng NG, Browne GJ, Lam LT, Yeoh R, Oomens M. Spacer compliance after discharge following a mild to moderate asthma attack. Arch Dis Child. 2002; 87:302-5.

28. Chorley JN. Ankle sprain discharge instructions from the emergency department. Pediatr Emerg Care. 2005;21:498-501.

29. Crain EF, Mortimer KM, Bauman LJ, Kercsmar CM, Weiss KB, Wissow L et al. Pediatric asthma care in the emergency department: measuring the quality of history-taking and discharge planning. J Asthma. 1999;36: 129-38.

30. De Maio VJ, Joseph DO, Tibbo-Valeriote H, Cabanas JG, Lanier B, Mann $\mathrm{CH}$, et al. Variability in discharge instructions and activity restrictions for patients in a children's ED postconcussion. Pediatr Emerg Care. 2014;30: $20-5$.

31. Demorest RA, Posner JC, Osterhoudt KC, Henretig FM. Poisoning prevention education during emergency department visits for childhood poisoning. Pediatr Emerg Care. 2004;20:281-4.

32. Gaucher N, Bailey B, Gravel J. For children leaving the emergency department before being seen by a physician, counseling from nurses decreases return visits. Int Emerg Nurs. 2011;19:173-7.

33. Hanson A, Drendel AL, Ashwal G, Thomas A. The feasibility of utilizing a comic for education in the emergency department setting. Health Commun. 2017;32:529-32.

34. Hawley CA, Unsworth L, Qureshi KL, Peachey T, Cooke MW. Discharge advice provided by UK emergency departments after minor head injury in children. Brain Inj. 2012;26:309-799.

35. Hemphill RR, Santen SA, Howell JM, Altieri MF. Follow-up compliance in febrile children: a comparison of two systems. Acad Emerg Med. 1998;5: 996-1001.

36. Johnson A. Do parents value and use written health information. Neonatal Paediatr Child Health Nurs. 1999:2:3-7.

37. Lawrence LM, Jenkins CA, Zhou C, Givens TG. The effect of diagnosisspecific computerized discharge instructions on 72-hour return visits to the pediatric emergency department. Pediatr Emerg Care. 2009;25:733-8.

38. Lawson LE, Patterson L, Corbin V. 446 parental knowledge and emergency department staff instruction involving child safety seat use after involvement in motor vehicle collisions. Ann Emerg Med. 2011;58:S329-30.

39. Ly CD, Dennehy CE. Emergency department management of pediatric asthma at a university teaching hospital. Ann Pharmacother. 2007:41: 1625-31.

40. Macy ML, Clark SJ, Cunningham RM, Freed GL. Availability of child passenger safety resources to emergency physicians practicing in emergency departments within pediatric, adult, and nontrauma centers: a national survey. Pediatr Emerg Care. 2013;29:324-30.

41. Melzer-Lange M, Lye PS, Calhoun AD. Advised follow-up after emergency treatment of adolescents with violence-related injuries. Pediatr Emerg Care. 1998:14:334-7.

42. Phillips W. Managing asthma in children —a guide for parents. Aust Nurs J. 2009;17:35.

43. Pizarro D, Posada G, Mohs E, Levine MM, Nalin DR. Evaluation of oral therapy for infant diarrhoea in an emergency room setting: the acute episode as an opportunity for instructing mothers in home treatment. Bull World Health Organ. 1979;57:983-6.

44. Qureshi KL, Hawley CA, Peachey T, Cooke MW, Unsworth L. Minor head injury in children: evaluating written discharge advice provided by Scottish emergency departments. Brain Inj. 2013;27:1549-54.

45. Ray M, Dayan PS, Pahalyants V, Chernick LS. Mobile health technology to communicate discharge and follow-up information to adolescents from the emergency department. Pediatr Emerg Care. 2016;32:900-5. 
46. Samuels-Kalow ME, Stack AM, Porter SC. Parental language and dosing errors after discharge from the pediatric emergency department. Pediatr Emerg Care. 2013;29:982-7

47. Sargant N, Milsom S. Designing a children's emergency department healthcare advice 'APP.'. Arch Dis Child. 2012;97(Suppl 1):A143.

48. Sarsfield MJ, Morley EJ, Callahan JM, Grant WD, Wojcik SM. Evaluation of emergency medicine discharge instructions in pediatric head injury. Pediatr Emerg Care. 2013;29:884-7.

49. Sauer MW, Hirsh DA, Simon HK, Schmitz ML, Sturm JJ. Effects of a systemwide fracture care program to enhance access and follow-up for orthopedics. Pediatr Emerg Care. 2012;28:680-3.

50. Stevens PK, Penprase B, Kepros JP, Dunneback J. Parental recognition of postconcussive symptoms in children. J Trauma Nurs. 2010;17:178-82. quiz 183-4

51. Thomas DG, Bradley L, Servi A, Reilly S, Niskala Apps J, McCrea M, Hammeke T. Parental Knowledge and Recall of Concussion Discharge Instruction. J Emerg Nurs. 2018:44(1):52-56

52. Wahl H, Banerjee J, Manikam L, Parylo C, Lakhanpaul M. Health information needs of families attending the paediatric emergency department. Arch Dis Child. 2011;96:335-9.

53. Waisman $Y$, Siegal $N$, Chemo M, Siegal G, Amir L, Blachar $Y$, et al. Do parents understand emergency department discharge instructions? A survey analysis. Isr Med Assoc J. 2003:5:567-70.

54. Waisman Y, Siegal N, Siegal G, Amir L, Cohen H, Mimouni M. Role of diagnosisspecific information sheets in parents' understanding of emergency department discharge instructions. Eur J Emerg Med. 2005;12:159-62.

55. Zonfrillo MR, Nelson KA, Durbin DR. Emergency physicians' knowledge and provision of child passenger safety information. Acad Emerg Med. 2011;18: 145-51.

56. Upchurch C, Morgan CD, Umfress A, Yang G, Riederer MF. Discharge instructions for youth sports-related concussions in the emergency department, 2004 to 2012. Clin J Sport Med. 2015:25:297-9.

57. Grover G, Berkowitz CD, Lewis RJ. Parental recall after a visit to the emergency department. Clin Pediatr (Phila). 1994;33:194-201.

58. Fung M, Willer B, Moreland D, Leddy JJ. A proposal for an evidenced-based emergency department discharge form for mild traumatic brain injury. Brain Inj. 2006;20:889-94.

59. Kaestli LZ, Noble S, Combescure C, Lacroix L, Galetto A, Gervaix A et al. Drug information leaflets improve parental knowledge of their child's treatment at paediatric emergency department discharge. Eur J Hosp Pharm. 2016;23:151-55

60. Delp C, Jones J. Communicating information to patients: the use of cartoon illustrations to improve comprehension of instructions. Acad Emerg Med. 1996;3:264-70

61. Ducharme FM, Zemek RL, Chalut D, McGillivray D, Noya FJD, Resendes S, et al. Written action plan in pediatric emergency room improves asthma prescribing, adherence, and control. Am J Respir Crit Care Med. 2011;183: 195-203.

62. Gorelick MH, Meurer JR, Walsh-Kelly CM, Brousseau DC, Grabowski L, Cohn J, et al. Emergency department allies: a controlled trial of two emergency department-based follow-up interventions to improve asthma outcomes in children. Pediatrics. 2006;117(4 Pt 2):S127-34.

63. Yin HS, Dreyer BP, van Schaick L, Foltin GL, Dinglas C, Mendelsohn AL. Randomized controlled trial of a pictogram-based intervention to reduce liquid medication dosing errors and improve adherence among caregivers of young children. Arch Pediatr Adolesc Med. 2008;162:814-22.

64. Baker MD, Monroe KW, King WD, Sorrentino A, Glaeser PW. Effectiveness of fever education in a pediatric emergency department. Pediatr Emerg Care. 2009:25:565-8.

65. Macy ML, Davis MM, Clark SJ, Stanley RM. Parental health literacy and asthma education delivery during a visit to a community-based pediatric emergency department: a pilot study. Pediatr Emerg Care. 2011;27:469-74

66. Stevens N, Drendel AL, Weisman SJ. Video Education Intervention in the Emergency Department. Acad Emerg Med. 2012;19(S1):S76. https://dalu-my. sharepoint.com/personal/navtran_dal_ca/NSR/Shared\%20Documents/ Full\%20Text\%20Articles/Stevens_abstract_2012.pdf. Accessed 22 Dec 2017

67. Bloch SA, Bloch AJ. Using video discharge instructions as an adjunct to standard written instructions improved caregivers' understanding of their child's emergency department visit, plan, and follow-up: a randomized controlled trial. Pediatr Emerg Care. 2013;29:699-704.
68. Ismail S, Mclntosh M, Kalynych C, Joseph M, Wylie T, Butterfield R, et al. Impact of video discharge instructions for pediatric fever and closed head injury from the emergency department. J Emerg Med. 2016;50:e177-83.

69. Chande VT, Wyss N, Exum V. Educational interventions to alter pediatric emergency department utilization patterns. Arch Pediatr Adolesc Med. 1996;150: $525-8$.

70. Boychuk RB, Demesa CJ, Kiyabu KM, Yamamoto F, Yamamoto LG, Sanderson $\mathrm{R}$, et al. Change in approach and delivery of medical care in children with asthma: results from a multicenter emergency department educational asthma management program. Pediatrics. 2006;117(4 Pt 2):S145-51.

71. Wood EB, Harrison G, Trickey A, Friesen MA, Stinson S, Rovelli E, et al. Evidence-based practice: video-discharge instructions in the pediatric emergency department. J Emerg Nurs. 2017;43:316-21.

72. Hart L, Nedadur R, Reardon J, Sirizzotti N, Poonai C, Speechley K, et al. 156: an interactive web-based module versus website and standard of care for parental fever education: a randomized controlled trial. Paediatr Child Health. 2015;20:e90.

73. LeMay S, Johnston C, Choinière M, Fortin C, Hubert I, Fréchette G, et al. Pain management interventions with parents in the emergency department: a randomized trial. J Adv Nurs. 2010;66:2442-9.

74. Isaacman DJ, Purvis K, Gyuro J, Anderson Y, Smith D. Standardized instructions: do they improve communication of discharge information from the emergency department? Pediatrics. 1992;89(6 Pt 2):1204-8.

75. Williams KW, Word C, Streck MR, Titus MO. Parental education on asthma severity in the emergency department and primary care follow-up rates. Clin Pediatr (Phila). 2013;52:612-9.

76. Patel B, Kennebeck SS, Caviness AC, Macias CG. Use of a discharge facilitator improves recall of emergency department discharge instructions for acute gastroenteritis. Pediatr Emerg Care. 2009;25:558-64.

77. Petersen DL, Murphy DE, Jaffe DM, Richardson MS, Fisher EB, Shannon W, et al. A tool to organize instructions at discharge after treatment of asthmatic children in an emergency department. J Asthma. 1999;36:597-603.

78. Considine J, Brennan D. Effect of an evidence-based education programme on ED discharge advice for febrile children. J Clin Nurs. 2007;16:1687-94.

79. To T, Wang C, Dell SD, Fleming-Carroll B, Parkin P, Scolnik D, et al. Can an evidence-based guideline reminder card improve asthma management in the emergency department? Respir Med. 2010;104:1263-70.

80. Porter SC, Forbes P, Feldman HA, Goldmann DA. Impact of patient-centered decision support on quality of asthma care in the emergency department. Pediatrics. 2006;117:e33-42.

81. Hussain-Rizvi A, Kunkov S, Crain EF. Does parental involvement in pediatric emergency department asthma treatment affect home management? J Asthma. 2009:46:792-5.

82. Zorc JJ, Scarfone RJ, Li Y, Hong T, Harmelin M, Grunstein L, et al. Scheduled follow-up after a pediatric emergency department visit for asthma: a randomized trial. Pediatrics. 2003;111:495-502.

83. Scarfi CA, Cunningham SJ, Wiznia A, Serebrisky D, Crain EF. Association between skin testing in the pediatric emergency department and adherence to follow-up in children with asthma. Ann Allergy Asthma Immunol. 2009;102:35-40.

84. Jones SL, Jones PK, Katz J. A nursing intervention to increase compliance in otitis media patients. Appl Nurs Res. 1989;2:68-73.

85. Zorc JJ, Chew A, Allen JL, Shaw K. Beliefs and barriers to follow-up after an emergency department asthma visit: a randomized trial. Pediatrics. 2009;124: $1135-42$.

86. Cushman R, Down J, MacMillan N, Waclawik H. Helmet promotion in the emergency room following a bicycle injury: a randomized trial. Pediatrics. 1991;88:43-7.

87. Kruesi MJ, Grossman J, Pennington JM, Woodward PJ, Duda D, Hirsch JG. Suicide and violence prevention: parent education in the emergency department. J Am Acad Child Adolesc Psychiatry. 1999;38:250-5.

88. O'Neill-Murphy K, Liebman M, Barnsteiner JH. Fever education: does it reduce parent fever anxiety? Pediatr Emerg Care. 2001;17:47-51.

89. Sockrider MM, Abramson S, Brooks E, Caviness AC, Pilney S, Koerner C, et al. Delivering tailored asthma family education in a pediatric emergency department setting: a pilot study. Pediatrics. 2006;117(4 Pt 2):S135-44.

90. Smith SR, Jaffe DM, Highstein G, Fisher EB, Trinkaus KM, Strunk RC. Asthma coaching in the pediatric emergency department. Acad Emerg Med. 2006; 13:835-9.

91. Rotheram-Borus MJ, Piacentini J, Cantwell C, Belin TR, Song J. The 18-month impact of an emergency room intervention for adolescent female suicide attempters. J Consult Clin Psychol. 2000;68:1081-93. 
92. Asarnow JR, Baraff LJ, Berk M, Grob CS, Devich-Navarro M, Suddath R, et al. An emergency department intervention for linking pediatric suicidal patients to follow-up mental health treatment. Psychiatr Serv. 2011;62:1303-9.

93. Komoroski EM, Graham CJ, Kirby RS. A comparison of interventions to improve clinic follow-up compliance after a pediatric emergency department visit. Pediatr Emerg Care. 1996;12:87-90.

94. Brooks TM, Smith MM, Silvis RM, Lerer T, Mulvey $\mathrm{CH}$, Maitland R, et al. Symptom-guided emergency department discharge instructions for children with concussion. Pediatr Emerg Care. 2017;33:553-63.

95. Leickly FE, Wade SL, Crain E, Kruszon-Moran D, Wright EC, Evans R. Selfreported adherence, management behavior, and barriers to care after an emergency department visit by Inner City children with asthma. Pediatrics. 1998;101:e8

96. Samuels-Kalow M, Rhodes K, Uspal J, Reyes Smith A, Hardy E, Mollen C. Unmet needs at the time of emergency department discharge. Acad Emerg Med. 2016;23:279-87.

97. Samuels-Kalow M, Hardy E, Rhodes K, Mollen C. "Like a dialogue": teachback in the emergency department. Patient Educ Couns. 2016;99:549-54.

98. Snilstveit B, Oliver S, Vojtkova M. Narrative approaches to systematic review and synthesis of evidence for international development policy and practice. J Dev Eff. 2012;4:409-29.

99. Caliva M, Stork C, Cantor R. Frequency of post-poisoning exposure information provided to patients requiring emergency care. Vet Hum Toxicol. 1998;40:305-6

100. Joseph D, Lee R, Tibbo-Valeriote H, De Maio V. Characteristics and Discharge Instructions for School Aged Patients Evaluated in a Community based Level 1 Trauma Centre Children's Emergency Department after Mild Traumatic Brain Injury. Acad Emerg Med. 2011;18(5):S163.

101. American Academy of Pediatrics Committee on Pediatric Emergency Medicine, American College of Emergency Physicians Pediatric Committee, \& Emergency Nurses Association Pediatric Committee. Joint policy statement-guidelines for care of children in the emergency department. Annals of Emergency Medicine. Ann Emerg Med. 2009;54:543-52.

102. Scottish Intercollegiate Guidelines Network. The SIGN discharge document. (SIGN publication no. 128). 2012. http://www.sign.ac.uk.

103. University of Michigan Health System. Discharge of Patients from the Emergency Department. 2012.

104. Newnham H, Barker A, Ritchie E, Hitchcock K, Gibbs H, Holton S. Discharge communication practices and healthcare provider and patient preferences, satisfaction and comprehension: a systematic review. Int J Qual Health Care. 2017;29:752-68.

105. Bellamy R. An introduction to patient education: theory and practice. Med Teach. 2004;26:359-65.

106. Grudniewicz A, Kealy R, Rodseth RN, Hamid J, Rudoler D, Straus SE. What is the effectiveness of printed educational materials on primary care physician knowledge, behaviour, and patient outcomes: a systematic review and meta-analyses. Implement Sci IS. 2015;10:164.

107. Koota E, Kääriäinen M, Melender H-L. Educational interventions promoting evidence-based practice among emergency nurses: a systematic review. Int Emerg Nurs. 2018;41:51-8.

108. Taylor DCM, Hamdy H. Adult learning theories: implications for learning and teaching in medical education: AMEE guide no. 83. Med Teach. 2013;35: e1561-72.

109. Merriam SB. Andragogy and self-directed learning: pillars of adult learning theory. New Dir Adult Contin Educ. 2001;89:3-14.

110. Badaczewski A, Bauman LJ, Blank AE, Dreyer B, Abrams MA, Stein REK, et al. Relationship between teach-back and patient-centered communication in primary care pediatric encounters. Patient Educ Couns. 2017;100:1345-52.

111. Slater BA, Huang $Y$, Dalawari P. The impact of teach-back method on retention of key domains of emergency department discharge instructions. J Emerg Med. 2017:53:e59-65.

112. Griffey RT, Shin N, Jones S, Aginam N, Gross M, Kinsella Y, et al. The impact of teach-back on comprehension of discharge instructions and satisfaction among emergency patients with limited health literacy: a randomized, controlled study. J Commun Healthc. 2015;8:10-21.

113. Centrella-Nigro AM, Alexander C. Using the teach-Back method in patient education to improve patient satisfaction. J Contin Educ Nurs. 2017:48:47-52.

114. Craig P, Dieppe P, Macintyre S, Michie S, Nazareth I, Petticrew M, et al. Developing and evaluating complex interventions: the new Medical Research Council guidance. BMJ. 2008;337:a1655.
115. Taylor DM, Cameron PA. Discharge instructions for emergency department patients: what should we provide? J Accid Emerg Med. 2000;17:86-90.

116. Tavender EJ, Bosch M, Gruen RL, Green SE, Knott J, Francis JJ, et al. Understanding practice: the factors that influence management of mild traumatic brain injury in the emergency department--a qualitative study using the theoretical domains framework. Implement Sci IS. 2014;9:8.
Ready to submit your research? Choose BMC and benefit from:

- fast, convenient online submission

- thorough peer review by experienced researchers in your field

- rapid publication on acceptance

- support for research data, including large and complex data types

- gold Open Access which fosters wider collaboration and increased citations

- maximum visibility for your research: over $100 \mathrm{M}$ website views per year

At BMC, research is always in progress.

Learn more biomedcentral.com/submissions 